\title{
18 Functionalist Approach
}

Ceramics are manufactured objects conceived to meet a variety of needs of both human groups and individuals. As people actively participate in their life context they rationalise their needs and adapt their activities in order to better solve existing problems. Thus, the active behaviour of people in pottery production produces end products which are more adapted to their needs and, therefore, highly functional.

Two key aspects characterise vessel life: the function they perform, which refers to the previous purposes of the potter, and their daily use (Rice, 1990, 1996). In this sense, the actions carried out by the potter when manufacturing an object involve certain intentionality towards the fulfilment of a particular objective or function. Therefore, ceramics meet some needs which are known and conceived before the same production of the pottery, so the future ceramic object tends to be manufactured according to these ideas. In this sense, the ceramic is created on the basis of specific performance criteria, irrespective of whether the vessel is eventually used or not.

In a materialistic sense, the technological choices that potters face along the chaîne opératoire define the final properties or performance characteristics of the pottery and, hence, its potential functions and uses. Therefore, during pottery production, the potter not only decides on his/her own actions, but also indirectly influences the behaviour and activities of other individuals who are also involved in the life cycle of ceramics. So, the study of the pottery itself and the identification of the procedures involved in its manufacture permits us to address the interactions existing between raw materials, techniques and fabrics according to their production and use processes (Braun, 1983; O’Brien et al., 1994; Rice, 1990; Schiffer, 2004; Schiffer and Skibo, 1987, 1997; Sillar, 2000; Sillar and Tite, 2000; Van As, 1984; Van der Leeuw, 1984).

This section focuses on functionalist theoretical perspectives that enrich the study of the relationship between the function of the vessels and the behaviour of potters in order to meet certain needs present in the world in which they live. Thus, the key concept is not whether ceramics are used or not, but just that they are created and preconceived to perform one or more functions. As already said, in functional studies the use is associated with the quotidian activities in which the vessels are involved and the several reuses that they may have. Although function and use often coincide, the latter does not necessarily match the function for which the pottery was created. In this way, most of the reuses of the vessels were non-existent in the mind of the potters, but they are provided by the consumers once the vessels are distributed. Furthermore, regarding the function, the main function for which the object is created should be conceptually differentiated from other secondary functions related to alternative uses of the artefacts. An example of the different functions associated with the same vessel is found in the cooking pottery from Pòrtol in Mallorca (Spain), whose main function is obviously to cook food. However, this pottery has other secondary 
functions such as to serve the food and keep it warm during its consumption (Albero and Puerta, 2011).

The secondary functions and uses of a pottery object are associated with its multifunctional character and the ability to achieve goals different from the primary purpose for which it was produced. Hence, although there can be other artefacts which are more effective, the features of one vessel usually allows its use in multiple activities. In short, ceramics respond at the time of their manufacture to one or more functions for which they are designed and intended. These functions can be simultaneously practical or utilitarian (e.g., cooking food or transport and store water) and symbolic and intangible (Aranda, 2001; Banning, 2005; Calvo, 1999, 2007; Hally, 1986; Sullivan, 1989; Vidal, 2008b).

It is absolutely necessary to study the characteristics of the ceramics to know whether their features obey certain functional specialisation or, conversely, whether they respond to other dynamics. It is, therefore, convenient to develop strategies of analysis tending to clarify and identify what kind of rationale guides the processes of production and use of the artefacts. In this way, the identification of pottery function and use can be undertaken through different procedures: analysis of absorbed residues, soot deposition patterns, analysis of surface micro-traces and macro-traces derived from use and maintenance activities, typological approaches, contextual analysis, etc. (Braun, 1983; Calvo et al., 2004b; Sillar and Tite, 2000; Skibo, 1992; Tite, 2008; Van As, 1984).

In this sense, and related to these functionalist concerns, the studies of ceramic fabrics, especially when combined with typological approaches, can also provide some valuable information to identify whether a functional adaptation exists or not in a certain vessel. As aforementioned, this functionalist viewpoint considers that potters are able to perceive the natural and social environment which surrounds them and, after a reflective process, they can consequently perform certain conscious technological behaviours in order to favour products that meet certain needs. Given this framework, approximations to vessel function can be made through the characterisation of the techniques and materials used in pottery production. As discussed earlier, both parameters determine fabrics with specific characteristics and end products with certain physical properties. Therefore, through this procedure it is possible to assess if the potter's technological choices respond to a strategy to maximize the efficiency of their fabrics and vessels to certain needs.

As many ethnographic studies evidence, it may be relevant to address the functional constraints and benefits of the materials and techniques used to manufacture ceramics fabrics, as well as of the features and properties of the end products. Thus, some clays and ceramic pastes, due to their particular properties, may be restricted to the production of vessels with certain characteristics and potential uses. In this way, experienced potters usually know the functional constraints imposed by the materials with which they work. For instance, in Tikul and Tepakán (Mexico) some potters are documented to use the same clay to manufacture the entire 
ceramic assemblage but prepare the paste differently depending on the function of the pottery (Arnold, 1985, 2000; Varela, 1990).

Cooking pottery is perhaps the kind of production that best exemplifies this functional adaptation of the potter's technological behaviour. It is considered that potters producing cooking wares must have in mind several key parameters (e.g., heat effectiveness, thermal shock resistance, abrasion resistance, etc.) in order to properly accomplish this function. Moreover, this assumption is confirmed by many ethnographic case studies. Thus, there are numerous modern societies in which potters select different raw materials depending on whether the pottery is going to be exposed to fire or not. This is the case, among many others, of potter communities from Quinua (Peru), Tabasco, Tikul or Durazno (Mexico) (Arnold, 2000), La Plata (New Mexico) (Armijo and Gallegos, 2008; Stoltman, 2001), Tonal'a, Thar and Swat (Pakistan) (Spataro, 2003) and the Shipibo-Conibo ethnic group in Peru (West, 1992). In the case of the pottery production from Pòrtol in Mallorca (Spain) (Albero and Puerta, 2011), non-calcareous red clays are selected to perform ceramics to be exposed to fire, while pale coloured calcareous raw materials are used to create ceramics used for storing and transport liquids. This basic division between cooking and non-cooking wares arranges the way pottery production is socially organised in the community and the different techniques and materials involved in the manufacturing process.

In addition, in many modern and ancient potter communities there is often a distinction between coarse-textured fabrics related to cooking wares and fine-textured ceramics associated with serving vessels. Moreover, non-cooking vessels are usually associated with fabrics which have a higher variability (Clop, 2007; Cuomo Di Caprio, 1985; Druc, 1996; Fernández Navarro, 2008; Kreiter et al., 2007; Muntoni et al., 2009; Ortega et al., 2005; Riley, 1982; Stoltman, 2001; Tite, 2008; West, 1992). For example, the use of clays with fine sands and few inclusions for producing storage vessels is ethnographically documented (Arnold, 2000). Similarly, the archaeological ceramics from Moundville (Alabama, USA) show a dual production in which the vessels related to service and storage functions are fine-textured. In contrast, cooking pottery is coarse-textured, showing grains around $2 \mathrm{~mm}$ in diameter and arranged according to a seriated distribution (Steponaitis, 1984).

These examples are evidence of how diverse pastes, fabrics and vessels related to different sizes and shapes as well as specific technological choices can be, in many cases, associated with distinctive functions. In these cases, the function of the vessel greatly affects its manufacturing process and, eventually, some of its features such as the fabric and physicochemical properties as well as the typology (Albero et al., forthcoming). In short, both the pottery production process and the end product are closely related to vessel function. These assumptions led to a theoretical view, developed in the 1980s, in pottery analysis called the science-based material approach, which has focused on the physicochemical properties of ceramic materials from a functionalist and evolutionary position. 


\subsection{Science-based Material Approach}

While ceramic materials may have distinctive significance and meaning in each culture, they also have certain universal physical features which are inherent in their nature. Consequently, the material behaves in the same way under similar conditions regardless of space or time. From this starting point, these studies attempt to demonstrate, through experimental research and the establishment of universal models, the possible adaptation of the vessels to different functions. Moreover, from these premises, this approach also aims at addressing the causes that promote technological change in pottery by means of the analysis of the end products.

All technology involves certain technical knowledge which is essential to its proper development. According to Schiffer and Skibo (1987), it is currently feasible to address the technological knowledge or the "techno-science" underlying ancient technologies through materials science. In other words, archaeologists can use materials science to search for the mental processes related to a particular technology through enquiring the role of each material feature of the artefacts according to specific functions. Eventually, this procedure permits postulating hypotheses based on the vessels' features concerning the technical knowledge that the potters had about the relations existing between the material dimension of the pottery and its functionality. Ultimately, through this approach it is also possible to approximate the needs of people and, therefore, their lifestyle. In this way, the functionalist approach considers that the "techno-science" is strongly related to the "techno-function", a concept which refers to the functional dimension of ceramic technology.

This theoretical trend has often tried to approach the "techno-science" and "techno-function" existing behind the pottery through ethnoarchaeology and experimental archaeology. However, ethnographic analogy has limited value when studying ancient technologies. As a consequence, these technological premises should be scientifically tested and validated by adequate experimental research programmes. Thus, the adequacy of pottery to diverse functions is therefore commonly assessed through experimental protocols ${ }^{21}$ focused on the analysis of the physical properties of pastes and fabrics. To this end, specific key parameters directly involved in certain potential functions of pottery are usually recorded. Hence, this experimental procedure permits us to identify and evaluate those features and physical properties of the ceramics which could have a greater significance for the potters when they conceived and produced the vessel in order to meet a specific function.

21 There are many examples of experimental research developed from this perspective (e.g., Bronitsky and Hamer, 1986; Hein et al., 2009; Hoard et al., 1995; Jordan et al., 2008; Kililikoglou and Vekinis, 2002; Kilikoglou et al., 1998; Müller et al., 2009; Schiffer, 1990a, b; Skibo, 1992; Skibo and Schiffer, 1987; Skibo et al., 1989; Tite, 2002; West, 1992; Young and Stone, 1990). 
Finally, it should be highlighted that the "ideo-function" can be approached from these materialistic, essentialist and universalistic models based on ethnography and experimental archaeology. This concept relates to those features of pottery technology that do not enhance the practical efficiency of the artefacts and, therefore, are supposed to be closely linked to certain cultural aspects also embedded in the processes of manufacture, use and deposition of the vessels. Thus, some authors of this theoretical school (e.g., Schiffer and Skibo, 1987, 1997) highlight that the benefits of interpreting the ceramic record in functional terms also underlie in the ability to identify which part of the artefact's technological variability can be related to its practical or utilitarian function and which not. In their opinion, this procedure therefore requires the researcher to address the extent to which practical and biological needs determine the technological behaviour of potters and the way they optimize their products according to specific productive capabilities.

Summing up, science-based material approach states that there are certain properties of ceramics which are especially relevant for the accomplishment of specific functions and they are, in consequence, much considered during the manufacturing process. These physical properties of materials are determined by the kind of inclusions, tempers and clays used to prepare the paste, as well as the techniques and tools used in the manufacturing process. In this sense, it is essential to approach the material dimension of pottery and the time invested in the manufacturing process in order to properly interpret the archaeological record and potters' behaviour. Thus, through the identification of pottery assemblages with different properties, it is possible to approach the potter's technological choices and his/her knowledge. Ultimately, all together (i.e., pottery, choices and knowledge) respond to the needs resulting from the lifestyle of individuals which can be, therefore, also indirectly addressed (Arnold, 2005; Christakis, 1999; Maniatis, 2002).

As already mentioned, the study of the properties of the vessels is undertaken through several key parameters (e.g., heat effectiveness, resistance to impact and abrasion, etc.) related to the physical characteristics of the pottery. Subsequently, these parameters can be summarised in a multifactor performance matrix (e.g., Fig. 18.4 and Fig. 18.5) which collects ceramic assemblages or fabrics with different technological attributes and certain properties. Hence, this matrix can be used to compare different ceramic assemblages in qualitative or quantitative terms (Pool, 2000; Prieto, 1999; Schiffer, 2004). The matrix based on the properties of the materials permits us to establish hypotheses concerning the behaviour of the individuals and the technical knowledge of the potters without making prior assumptions about the reasons that conditioned the optimisation or minimisation of specific characteristics in the materials. Moreover, the comparison of the physical properties characterising different technologies can be undertaken without any restriction in the number or kind of parameters involved in the analysis. Subsequently, this multifactor matrix can be used to deductively evaluate assumptions previously established from certain theoretical frameworks (Schiffer, 2004). 
In conclusion, the theoretical foundations of the science-based material approach may be useful to interpret the archaeological record and evaluate the criteria underlying pottery technology through the study of the physical traits of materiality (Tite, 2008). In the following paragraphs some of the main parameters analysed in the studies of ceramic pastes and fabrics through science-based material approaches and its impact in pottery production process will be addressed.

\subsubsection{Thermal Shock Resistance}

As ceramics are poor conductors of heat energy, sudden temperature changes cause a differential heating along the vessel wall. Because the external margin of the vessels heats and cools more quickly than the internal margin, a slight delay in the transmission of temperature through the vessel is generated. In this sense, the higher the delay in the distribution of heat along the ceramic body, the higher the temperature difference between different points of the vessel wall and, therefore, more severe the thermal shock. Technically, any pottery will eventually break as a result of the continuous alternation of heating and cooling thermal cycles. This breakage can led to a higher need of pottery replacement, especially in ceramics used for cooking purposes. Thus, thermal shock resistance is defined as the property of the walls to shrink and expand without cracking. This is a complex process which involves several physical parameters such as porosity and homogeneity of the fabric, firing temperature, thermal conductivity, thermal expansion and elasticity of the material, as well as the shape of the components present in the paste (Bronitsky and Hamer, 1986; Morales, 2005; Müller et al., 2009; Steponaitis, 1984; West, 1992).

All these aspects affect the capacity of the walls for preventing the formation and propagation of fractures (West, 1992). In this sense, as will be seen, in low-fired pottery one viable option consists in reducing the differential thermal expansion of the several components present in the paste, thereby minimising the number of cracks appearing in the firing process. In any case, it is impossible to entirely avoid the generation of fractures in non-vitrified fabrics, thus it is more efficient to prevent the propagation of the fractures already generated. Through this strategy, although some fractures are generated in the vessel wall, it is fairly easy to create relatively intact and usable ceramics. Despite the fact that this would be the best option to promote thermal shock resistance in low fired ceramics, it should be considered that the higher the firing temperature the harder the wall of the vessel and then, the higher the energy required to initiate a fracture (Müller et al., 2009).

As already mentioned, several parameters are involved in the capability of the vessel walls to prevent the propagation of the fractures generated. In this sense, once a fracture is initiated in the ceramic body, its possibility to spread is related to the energy contained therein. The distance at which the fracture propagates is proportional to the amount of energy present in the moment at which the crack 
was originated. This energy can be reduced by increasing the fracture surface, thus allowing the components of the vessel wall to partially absorb and reduce the stress generated. In this way, fractures are localised in the internal pores and around the non-plastic components, thus favouring quasi-static crack growth. Furthermore, fracture energy is also distributed along the vessel wall through the initiation and propagation of secondary fractures derived from a main crack which collided with a non-plastic component. This process prevents and minimises the concentration of the fracture energy into a single point of the ceramic body, thereby reducing the risk of pottery collapse.

In short, strength and toughness are parameters to take into account in pottery production since they are related to the ability of the vessel walls to resist crack initiation and to absorb fracture energy without failure (see Tite et al., 2001). In this sense, the best way to enhance vessel strength against thermal shock in ancient ceramics seems to have been to increase the effective fracture surface energy. Thus, in order to influence this parameter, potters had to consider the raw materials they select to make the vessels, especially if the pottery was going to be used in cooking activities. In consequence, many potters utilized a discriminating strategy in which only certain clays and tempers were selected.

For instance, as already mentioned, in some cases there is a clear rejection to use calcareous clays for the manufacture of cooking pots, since they have a higher thermal expansion coefficient than non-calcareous clays. Thus, in cooking vessels of the Iron Age from Galilee (Shoval et al., 2006) or Late Roman pottery from northern Syria (Howard, 1982; Schneider et al., 2007) potters preferred to use non-calcareous or border calcareous materials to manufacture ceramics which are more stable when exposed to direct contact with fire. This technological choice created fabrics which are capable to resist repetitive processes of cooling and heating without breakage, thus increasing the durability of the vessels (West, 1992).

The texture of the fabrics is a key parameter to take into account in order to achieve thermal shock resistance in low-fired ceramics. Coarse-textured fabrics with abundant mineral inclusions or tempers significantly increase the effective fracture surface, favouring the formation of micro-pores around the non-plastic components, preventing the propagation of fractures and the subsequent breakage of the vessel. Therefore, the amount and size of inclusions and tempers largely determines the resistance to thermal shock in prehistoric pottery. Fabrics with abundant coarse grains reduce the propagation length of a fracture in the vessel wall, since a greater amount of energy is absorbed by increasing the diameter and length of the particles. The maximum size and amount of non-plastic material that can be present in the paste is determined, first, by the thickness of the wall. Thus, particle-size has to be finer than vessel walls width; otherwise the propagation of the fractures along the grains could dangerously affect the integrity of the vessel. Second, the amount of non-plastic components is also conditioned by the workability of the paste. If the raw materials have too many inclusions or excessive temper is added to the clay, the workability 
of the paste will be significantly reduced. As seen, the potter should achieve, then, certain balance between several parameters such as vessel wall thickness, the workability of the materials and their thermal shock resistance (West, 1992).

Summing up, although pottery strength mainly depends on firing temperature, the presence in the fabric of a large amounts of coarse-sized minerals and rock fragments provides some toughness to the vessels, since it avoids the propagation of fractures resulting from differential stress in different points of the object. The relation observed in multiple potter communities between coarse fabrics and cooking pots demonstrates that, from a structuralist perspective, there are logical cognitive structures that humans share regardless of particular historical processes (Dietler and Herbich, 1998), that is, that certain universal perception of physical phenomena exist.

Potters worldwide can easily manufacture ceramics which are suitable for this function. On the one hand, many potters, for example in Durazno, Quinua and Swat (Arnold, 2000), select raw materials with coarse sand and abundant inclusions to produce cooking pottery. However, on the other, some types of clay are too fine and do not possess these textural characteristics. In these cases, the addition of large quantities of coarse mineral temper to the clay improves the thermal behaviour of the vessels, regardless of the kind of temper used (Riederer, 2004; Steponaitis, 1984; West, 1992). For example, in Tikul there are some potters that collect the same clay for all the types of vessels but use different tempers depending on the function of the pottery (Arnold, 2000).

Experimental studies demonstrate that, in comparison with non-tempered clays, clays tempered with either mineral or organic materials improve their thermal shock resistance. Actually, any kind of temper makes the vessels suitable to withstand thermal shock (Schiffer and Skibo, 1987), so that if the pottery survives the firing process it can be considered valid for cooking. This assumption explains on the basis of material behaviour the wide variety of tempers that are documented in cooking vessels worldwide. However, as highlighted in the section on ceramic ecology, the accessibility and proximity to temper materials seem to determine their selection, being the use of sands and crushed rocks the most widespread choices recorded.

For instance, the use of quartz or coarse-grained sands as temper in cooking pots is well documented in the United Kingdom from the Neolithic to the Middle Ages (Tite et al., 2001; West, 1992; Woods, 1986). The same choice is observed in Syria during the Late Roman period (Schneider et al., 2007). Furthermore, at the archaeological sites in Mycenae (Riley, 1982; West, 1992) or in Late-Roman wares from Sa Mesquida in Mallorca (Cau, 2003) the use of igneous rocks to temper cooking pots is documented. Other cooking vessels are characterised by the use of spathic calcite, such as the ceramics made from terra rossa clays in Galilee during the Iron Age (Shoval et al., 2006), Neolithic pottery from south-eastern Italy (Muntoni et al., 2009) or Late Roman cooking wares from north Africa (Bonifay, 2007). This temper is also ethnographically documented in Tikul (Yucatan, Mexico), where it is exclusively added to cooking pots (West, 1992). Other potters added crushed shell or limestone to their cooking wares. 
This is the case of the prehistoric vessels from Alabama, Illinois and Missouri in North America (Braun, 1983; Feathers, 2006; Hoard et al., 1995; Skibo, 1992; Stepoinatis, 1984) or the Neolithic pottery from the Orkney Islands (Jones, 2002). Finally, cooking vessels from Pakistan are tempered with a mixture of grog and quartz. Moreover, in this case, tempers are differentially distributed in the different parts of the vessels (Spataro, 2004).

There are several factors to consider when assessing the properties of the temper added to the paste and their influence in the end product. Each material has different physical properties which constrain or expand the stress in the vessel walls when exposed to fire. Thus, a given temper can either promote or prevent the emergence and spread of fractures in the pottery.

\section{a) Thermal Expansion}

The varied components of the paste respond differently to the application of heat and have diverse dilatometric behaviour, thus resulting in a differential stress in the pottery. Thus, in modern industry it is common to intentionally promote a reduction in the thermal expansion coefficient of the several constituents that form the ceramic body. This reduction is achieved through the use of high firing temperatures and the formation of a glassy phase which prevents the initiation of cracks in the vessels (West, 1992).

The different clays have a quite similar thermal expansion coefficient but, in contrast, the non-plastic components of pastes and fabrics usually have differential thermal coefficients from the clay matrix. This dilatometric divergence increases the energy flowing through the ceramic objects, thus favouring crack initiation and the propagation of fractures throughout the vessel walls. The energy present in the matrix is proportional to the coefficient of thermal expansion of the minerals.

Therefore, the use of temper with a thermal expansion coefficient similar to the clay (e.g., spathic calcite or shell) provides more strength to the pottery while also preventing the emergence and propagation of fractures due to dilatometric divergences as a result of repetitive cooling and heating processes. In this way, the use of grog is highly recommended, since this temper is mainly composed of clay and, therefore, has a lower thermal expansion coefficient. However, this temper provides little resistance to thermal shock. The reason is that the high amounts of clay minerals of grog do not efficiently reduce fracture propagation and allow the cracks to go through the particles, especially if the grog fragments lack non-plastic components. In contrast to grog or calcite, other tempers have a higher rate of thermal expansion. This is the case of quartz, a mineral which, as already mentioned, experiences a change of phase at $573^{\circ} \mathrm{C}$. Therefore, the dilatometric changes which occur at this temperature may cause considerable stress in the pottery when this mineral is present in significant amount, thus generating crack initiation and propagation in the vessel walls. Hence, low amounts of fine-grained quartz reduce the negative effects of differential thermal expansion in the paste and the fabric, thus preventing the initiation of fractures 
(Hoard et al., 1995; Kilikoglou et al., 1998; Rye, 1976; Shoval et al., 2006; Steponaitis, 1984; Tite, 2008; Tite and Kilikoglou, 2002; West, 1992; Williams, 1982).

b) Morphology of the Particles

The morphology of the non-plastic components present in pastes and fabrics is another relevant parameter to be considered in order to reduce thermal shock in the pottery. The more efficient tempers and inclusions for this purpose are those which have platy shapes, such as mica-schist. In this way, mica is a quite common temper in cooking wares produced by multiple traditional societies from North America (West, 1992). Therefore, particle shape and its orientation along the vessel margins determine certain physical properties of the end product. In this sense, grog and quartz grains are usually equant and, therefore, do not exhibit any preferential orientation in the matrix. In contrast, other materials such as shell or mica have an elongated or prismatic habit that promotes a parallel alignment of the particles along the vessel surfaces. As previously noted, this preferential orientation results from the pressure the potters promote when kneading the paste and modelling the vessel. This particle morphology increases effective fracture surface energy, thus providing pastes and fabrics with higher resistance to crack propagation than others with abundant equant grains. The reason is that the fractures caused by thermal shock usually initiate in the vessel surface and propagate to the core of the wall through its weaker parts. In their expansion, fractures collide against platy or elongated tempers and inclusions which act as barriers. Fractures require less energy to surround the particles than to go through them, therefore the greater surface of these components permits to absorb higher amount of the fracture energy, avoiding crack propagation. In short, the presence of elongated or prismatic components minimises the expansion of fractures within the ceramic body and, ultimately, results in cooking vessels that have greater durability than the ones tempered with grog or sands (Müller et al., 2009; Steponaitis, 1984; Tite and Kilikoglou, 2002; West, 1992).

\section{c) Porosity}

Thermal shock resistance also depends on the size, shape and distribution of the pores in the pottery microstructure. Small elongated micro-pores originated as a consequence of paste shrinkage during the drying stage conduct the fractures initiated and propagated along the vessel until they lose energy in non-plastic components. Nevertheless, fabrics with high open porosity in which the pores connect with the vessel surfaces are not recommended for cooking wares. The reason is that this pore configuration significantly reduces the thermal effectiveness and thermal shock resistance of the fabrics, two key parameters that are crucial to achieving efficient cooking wares. Furthermore, it should be remembered that while fabrics having their inclusions and tempers oriented perpendicularly to the point of fracture propagation have greater resistance to thermal shock, they also reduce heating effectiveness. Moreover, large pores are unsuitable for cooking vessels, especially if they go cover 
nearly all the vessel wall thickness, since it is easier to achieve the fracture length required to cause severe cracks in the pottery. Finally, pores are quite ineffective to deflect the energy of fractures through the formation of secondary cracks, so being of limited value to prevent fracture propagation along the vessel (Gibson and Woods, 1990; Skibo, 1992; Steponaitis, 1984; Velde and Druc, 1999; West, 1992).

\section{d) Firing Temperature}

As stated before, although the firing temperature greatly determines the strength of the vessel, fabrics with abundant temper fired at low temperatures also have high thermal shock resistance. Thus, the fracture strength of the fabric increases according to the amount of temper added to the paste (Müller et al., 2009). In this way, experimental tests performed with calcareous clay demonstrated that it is possible to maximise the toughness of the pottery without reducing its fracture strength if $20 \%$ of the volume of the vessel is constituted by quartz temper and firing temperatures between $950^{\circ}-1100^{\circ} \mathrm{C}$ are achieved (Steponaitis, 1983, 1984; Tite et al., 2001).

However, these high temperatures were rarely achieved in many prehistoric pottery production centres. As low fired pottery has a lower thermal shock resistance than other fired at high temperature it is also most vulnerable. Even so, vessels may still be considered efficient if they have at least $20 \%$ of mineral non-plastic components and are fired at $750-800^{\circ} \mathrm{C}$ (Bronitsky and Hamer, 1986; Skibo et al., 1997). Hence, the technical solutions observed in many prehistoric ceramics, characterised by the use of coarse fabrics, favours obtaining pottery fired at low temperatures $(<750$ $800^{\circ} \mathrm{C}$ ), and which is therefore relatively resistant to thermal shock (Shoval et al., 2006). Moreover, the use of low firing temperatures has certain advantages in pottery production. For instance, low firing temperatures decrease the rigidity of the fabrics, thus promoting unglazed and porous fabrics that have certain ability of torsion and contraction. Therefore, this property prevents the occurrence of fractures derived from the expansion of the walls due to differential heating, thus avoiding severe damage in the vessel. In contrast, vitrified fabrics are quite rigid and cannot shrink adequately when the wall expands and contracts due to heating and cooling processes (Gibson and Woods, 1990).

\subsubsection{Heat Effectiveness}

Other properties of ceramics which play a key role in cooking activities are heat efficiency and thermal conductivity. These parameters refer to the distribution and intensity of heat along vessel walls, as well as the rate at which heat spreads along the pottery (Morales, 2005). It can be assumed that in many cases the transmission of heat energy to the pottery was carried out from domestic hearths and using fire. Therefore, heat propagation mainly took place through thermal conduction, i.e., heat 
is transmitted from one molecule to another from the external to the internal surface of the vessel (Cuomo Di Caprio, 1985).

Heat effectiveness is a parameter rarely explored through experimental tests in ceramic studies which is crucial to enable certain cooking methods (Hein et al., 2009). Thus, the study of this parameter is important in the research of pottery technology in order to determine, for instance, if an ancient fabric was apt for boiling or not, the time needed to reach the boiling point and the amount of fuel to be consumed in order to achieve this purpose. Cooking methods can affect many aspects of daily life, from the way food is prepared to the range of foodstuffs available for human consumption. In this way, cooking methods such as steaming or boiling are used in many societies in order to reduce and eliminate the toxins present in many food products, thus allowing their ingestion. These cooking methods are ethnographically documented as quite effective to sterilise foodstuffs contaminated with bacteria and fungi (Arnold, 1985). In short, pottery is required in certain methods of food preparation that expand the range of food products available for consumption, thus increasing the quality of life and life expectancy of individuals. Eventually, the introduction of new cooking methods and foodstuffs may provoke even demographic changes (Wright, 1991).

The variables that most influence the heat effectiveness of the fabrics are the firing temperature, porosity, texture and thickness of the vessel wall (Hein et al., 2009; Hoard et al., 1995; Morales, 2005; West, 1992). These parameters are greatly determined by the manufacturing process, thus involving the type of clays, tempers, forming methods, surface treatments and firing procedures used to produce the vessels.

There must be a balance in the degree of porosity of the fabric, since the heat conduction from one surface of the vessel to the other basically takes place through the internal pores in the wall, especially if the pores are interconnected. In this sense, the presence of some porous in the fabric may be advisable to favour heat conductivity (Rye, 1976). However, an excessive open porosity may significantly reduce the heat effectiveness of the vessel because the content that filters to the exterior of the pottery through the pores has to be heated first before the heat reaches the content of the vessel. Therefore, extremely porous fabrics, such as those rich in organic matter, decrease their heat effectiveness and require more time and energy investment to heat their content. In addition, the morphology of the pores is also involved in this process, since certain types of pores can act as barriers, thus constraining heat spreading (Hein et al., 2009; Müller et al., 2009).

The disadvantages of the high porosity, usually resulting when calcareous pastes are fired between $800-950^{\circ} \mathrm{C}$, could also explain, along with their higher thermal expansion coefficient, why many potters reject the use of these kinds of materials to produce cooking pottery. In this range of firing temperature much of the calcite present in the paste reacts, thus leaving a large amount of vacuoles or pores which connect to the vessel surfaces and reduce thermal efficiency. As experimentally recorded, the addition of temper such as sands or spathic calcite crystals allows greater efficiency 
in this variable, since it reduces the open porosity and increase the micro-porosity of the fabric (Hoard et al., 1995).

The addition of organic matter also increases the open porosity and microporosity of the fabrics (Albero, 2010) providing elongated pores which, up to a point, favour heat conductivity through vessel walls (Rye, 1976). However, the high amounts of open pores that characterise theses kinds of fabrics may neutralise their supposed benefits. Some experiments demonstrated that the addition of sand or other mineral tempers to pastes rich in organic matter improve the thermal efficiency of these sorts of fabrics. The addition of organic matter, it seems, results in pottery vessels with a better heat efficiency than non-tempered clays having just a few inclusions. Nevertheless, it should be concluded that fabrics with abundant non-plastic mineral components are the most suitable to achieve high heat effectiveness (Skibo, 1992; Schiffer and Skibo, 1987).

Besides the problem of excessive porosity, the use of pastes rich in organic matter also increases the thickness of vessel walls. As discussed earlier, wall thickness also influences heat effectiveness, since the thinner the wall, the faster and more intensely the heat is spread through the ceramic body and its surfaces. The reduction of wall thickness, through the addition of certain tempers to the paste, for instance, promotes heat effectiveness, especially if the fabric is composed of refractory tempers such as quartz (Olatexea, 2000).

There are some experimental tests that well exemplify the assumptions just mentioned. Vessels with mineral tempers such as sands are demonstrated to have higher heat efficiency, since they are capable to boil water and reach $92.4^{\circ} \mathrm{C}$ in only 7.8 minutes. In contrast, pastes tempered with organic matter are useless to boil water and the maximum temperature reached after 10 minutes is $86.1^{\circ} \mathrm{C}$. These differences are related to the higher wall thickness and porosity that results from the use of pastes rich in organic matter. Consequently, these kinds of fabrics have greater water absorption and, therefore, the liquids must evaporate first from the many pores of the ceramic body before the content can boil. Thus, this experiment demonstrates that fabrics with high porosity have little heat effectiveness and consume higher amounts of fuel (Schiffer and Skibo, 1987; Skibo, 1992; Skibo et al., 1989). Moreover, one would expect a weak correlation between this kind of fabric and cooking methods such as boiling.

The high porosity resulting from the use of pastes rich in organic matter or calcareous clays which affects negatively heat effectiveness can be corrected through the application of natural resins or slips on the vessel surfaces. For instance, Kalinga potters (Philippines) usually apply pine resins on both surfaces of all their ceramic assemblage except in cooking vessels. In the latter type of pottery the resin is only present in areas which are not exposed to fire, i.e., the inner surface of the vessels and the outer surface of the rim and the neck (Skibo, 1992). Moreover, this technical choice is also performed by potter communities from Cameroon (Gosselain et al., 
1996). Surface treatments like this one reduce the open porosity of the ceramics and minimise heat loss, thus providing more efficient products.

However, not all surface treatments improve the heat efficiency of the pottery. Some experimental tests demonstrate that the application of techniques such as polishing or corrugated and excised decorative patterns on the surface of the vessels may reduce significantly their heat effectiveness (Schiffer, 1990a; Schiffer and Skibo, 1987; Skibo, 1992; Tite, 2008; Tite et al., 2001; Young and Stone, 1990). It may explain, for instance, why prehistoric cooking pots from Moundville (Alabama, USA) were not burnished (Stepoinatis, 1984). Nevertheless, there are also other traditional potter communities, for example in Chile, where the use of this surface treatment is well documented for the production of cooking vessels (García Rosselló, 2008).

Finally, heat effectiveness may be also influenced by specific pottery typologies or shapes. Therefore, the physical properties related to certain typologies may ultimately influence aspects such as human diet and the use of certain cooking methods. In this way, globular vessels have a higher surface directly exposed to fire and hence enhance their heat effectiveness and thermal conductivity. For this reason, it is advisable to use hemispherical rather than flat bases, especially if the pottery is going to be used over a hearth delimited with stones. In this sense, it should be noted that hemispherical bowls are widely used for cooking purposes in many traditional societies (Albero and Puerta, 2011; Arnold, 1985; Barley, 1994; Kramer and Balagizi 2009), thus indicating that such bases may provide end products with a higher thermal efficiency, which is useful for cooking activities. In addition, heat propagation along vessel walls makes the presence of handles or other prehension elements necessary in the pottery, preferably close to the rim where there a is lower concentration of heat, in order to remove the vessel when it is hot. Therefore it is not surprising that this appendix is found in many cooking pottery productions (Fernández Navarro, 2008; Schiffer and Skibo, 1987; Tite and Kilikoglou, 2002).

\subsubsection{Abrasion Resistance}

The abrasion of the surface of the vessels occurs as a consequence of repeated exposure to the fire for prolonged periods of time. Continuous exposure to heat causes physical and chemical erosion of the vessel walls which gradually reduce their heat effectiveness and thermal shock resistance. Although such processes have negative effects which may reduce significantly the life expectancy of the pottery, they can be partially minimised by the addition of mineral temper to the paste. Thus, the presence of abundant coarse-grained quartz, mica or shell to the fabric is demonstrated to reduce the effects of abrasion (West, 1992).

This reason explains why it is common to find this kind of texture in cooking wares which, given their function, require necessarily high mechanical strength to be repeatedly used (Tite et al., 2001; Woods, 1986). In addition, in order to improve 
abrasion resistance, the temper added to the paste can be arranged following a seriated or polymodal distribution. In contrast to a unimodal disposition of the particles, these kinds of grain distributions improve the matching between temper elements, thus also improving the compactness of the end product and reducing its porosity (Cuomo Di Caprio, 1985).

Fabrics with abundant porosity, in contrast, such as those rich in organic matter, are quite affected and abraded by such erosive processes, even more than non-tempered clays. The pores promote the penetration into the vessel walls of the chemical corrosive acid substances the pottery comes in contact with. As a consequence, although cooking pots tempered with organic matter may be used to undertake certain cooking methods, their use life is substantially reduced. They show little resistance to abrasion and are severely damaged when repeatedly exposed to the fire (Skibo and Schiffer, 1987; Skibo et al., 1989).

The impact of abrasion in the vessels can be minimised by increasing firing temperature. Thus, it seems that firing temperature is the parameter which most influences this variable, even more than the characteristics of the paste used to manufacture the pottery. Firing temperature should be high enough to allow efficiently cooking foodstuffs. As already mentioned, the neoformation of phyllosilicates may take place in low-fired pottery $\left(<550^{\circ} \mathrm{C}\right)$, thus recovering their initial structure and properties and thereby making the vessels unsuitable for cooking purposes. On the one hand, the neoformation of clay minerals provokes some stresses in vessel walls when pottery containing water is exposed to fire for a long time. The reason is that the clay minerals expand when they hydrate and, subsequently, shrink due to their dehydration by heat. Moreover, clay minerals eventually absorb air humidity and can recover certain plasticity and turn back to their natural state. These physicochemical changes in the clay minerals generate abrasive processes which disappear by increasing the firing temperature and, especially, through the formation of a glassy phase in the matrix (Gibson and Woods, 1990; Núñez et al., 2002).

Furthermore, there are other attrition processes which also promote the erosion of ceramic walls different from those that depend on the contact with the fire. On the one hand, the attrition of the pottery walls also occurs due to the repetitive friction and scraping that the individuals carry out on the vessel surfaces in order to clean the pottery (Skibo, 1992). On the other, there are natural erosive agents such as frost that affects the pottery when the moisture contained in the pores of the fabric becomes ice at below zero temperatures. This change of liquid to solid state involves an alteration in volume, since the volume of ice is greater than the one of liquid water. This difference causes a large stress in the pottery, favouring the initiation and propagation of fractures along the vessel wall. This abrasive process is especially significant and harmful when the fabric has high number of macro-pores and they are concentrated in specific areas of the clay matrix. This pore arrangement intensifies the energy resulting at specific points of the wall which, therefore, become more susceptible to fracture. This same process can occur also as consequence of the 
salts diluted in water which naturally exist in the environment or are formed through the migration of the content of the ceramics through the pores of the wall. The salts that progressively crystallise in the pores of the pottery undergo changes in volume, creating and propagating cracks in the walls. To avoid this negative process, pastes have to be well prepared and fired, thus favouring homogeneous fabrics with low porosity (Morales, 2005).

Finally, it should be highlighted that the attrition of ceramics resulting from all these processes can be reduced by applying resins on the vessel surfaces. Unfortunately, the remains of such organic materials eventually disappear without leaving any trace. In contrast, experimental tests demonstrate that other surface treatments such as polishing or scraping do not improve the abrasion resistance of the pottery (Schiffer, 1990a; Skibo et al., 1997; Velde and Druc, 1999).

\subsubsection{Impact Resistance}

Mechanical strength refers to the weight per unit area required to cause fracture in the vessel wall. This parameter is largely determined by the compactness of the fabric, in so far as pottery is more resistant when it is more compacted (Cuomo Di Caprio, 1985). Resistance to impact relates to both direct bumps on the vessel walls and impacts derived from their fall due to a potential loss of stability. In the latter case, the weight of the pottery itself must be taken into account, since the impact force from a falling object also depends on its mass.

Impact resistance is a key parameter to be fully considered in all kinds of ceramic wares, but it is especially significant in those used to store contents. Thus, there is a greater risk of losing the products if the storage vessels break easily, especially if the contents are of a liquid or semi-liquid nature. Certain resistance to sudden impact is also desirable to some extent in cooking wares when they are also used to serve food, as occurs with the cooking pots from North Africa and Mallorca (Albero and Puerta, 2011), as well as in Nazarí cooking vessels (Fernández Navarro, 2008). In addition, it is also advisable that the vessels resist some pressure in cases in which they are stored stacked on top of one another.

Mechanical strength influences impact strength, which can be defined as the ability of a solid to withstand forces applied in a specific point on its surface. Resistance to impact is largely determined by the ability of the vessel walls to contract and absorb impact energy without causing fractures. In this sense, fabrics with moderate amounts of non-plastic mineral components have better impact resistance. What is more, the evidence suggests that fine-textured pottery has more mechanical resistance to impact to mechanical shock than ceramics with a high frequency of inclusions and tempers (Bronitsky and Hamer, 1986; Christakis, 1999; Kilikoglou and Vekinis, 2002). Therefore, the lower the amount of non-plastic components present in the paste, the higher the contraction capacity of the clay matrix and the greater the 
possibility to prevent breakage, thus increasing the resistance to impact of the fabric (Stepoinatis, 1984).

Despite these assumptions, differences observed in impact resistance between tempered and non-tempered clay experimental samples fired at low temperatures $\left(550^{\circ}-650^{\circ} \mathrm{C}\right)$ are not much significant. So, it can be argued that this parameter is not relevant in low-fired pottery productions. In contrast, at higher temperatures $\left(750^{\circ}-850^{\circ} \mathrm{C}\right)$ there are greater differences in the resistance to impact of the vessels depending on the kind of material used (e.g., mineral or organic matter) to temper the pots (Skibo et al., 1989). Moreover, experimental tests show that resistance to impact is largely influenced by firing temperature. At higher firing temperatures, the pottery develops greater compactness, hardness and rigidity; consequently, fractures are more difficult to initiate. However, when a crack is generated and propagates through the vessel wall it becomes more critical, since fabrics related to ceramics fired at high temperatures have a lower capacity to shrink (West, 1992).

\subsubsection{Cooling Effectiveness}

Cooling effectiveness is the property of the vessels that determines their ability to properly preserve food, a parameter particularly relevant in ceramics which are used to store and transport contents over extended periods of time. In such pottery, the porosity and permeability of the fabric allows part of the content to flow through the wall of the vessel. The liquid contents in the pores closest to the external surface of the pottery is removed through air evaporation, thus reducing the temperature inside the vessel and favouring the cooling of the content of the pottery below air temperature. A proper perspiration prevents fungi growth or the loss of the contents by excessive evaporation, keeping the product fresh and in good storage conditions, thus extending its expiration date. Therefore, ceramics with a relatively high porosity are ideal to store water and other liquids in arid or dry climatic conditions characterised by low relative humidity. However, it should be noted that an excessive porosity and permeability can have negative consequences, as it may result in a significant loss of the contents (Arnold, 1985; Palomar, 2005).

In this way, for instance, the use of calcareous fabrics does not involve, a priori, any problems providing efficient cooling. On the contrary, the initial decomposition of calcium carbonates in pottery fired at low temperatures $\left(650^{\circ}-750^{\circ} \mathrm{C}\right)$ favours the formation of a porous microstructure that provides the minimum perspiration required for adequately preserving both liquid contents such as water and solid products like grain (Palomar, 2005). Thus, it is hardly surprising to find ethnographical (e.g., Albero and Puerta, 2011) and archaeological (e.g., Shoval et al., 2006) records that exclusively use calcareous fabrics to produce storage pots and tableware.

Some experimental research (Schiffer and Skibo, 1987; Skibo et al., 1989) concludes that similar and satisfactory results are obtained by the addition of both mineral temper and organic matter to the paste. Pottery tempered with sand and fired 
at $650^{\circ} \mathrm{C}$ is quite permeable and maintains the content at a constant temperature of $19.6^{\circ} \mathrm{C}$. In short, it appears that different fabrics fired at low temperatures are equally efficient for preserving foodstuffs, even in arid environments associated to extreme climate conditions.

However, fabrics with excessive porosity, such as those very rich in organic matter, may have less cooling efficiency, especially if abundant pores are interconnected with the vessel surfaces. Thus, excessive porosity and permeability can be counterproductive, since it may involve the physical loss of the contents and an inadequate perspiration of the substances which will eventually spoil the container capacity. In any case, it is stated that the evaporation of the content is a parameter strongly influenced by the environmental conditions (e.g., humidity, wind, etc.) in which ceramics are located (Schiffer, 1990b).

Such negative effects can be minimised through the application of certain inorganic and organic materials on vessel surfaces. Thus, materials such as slips made from very fine clays or techniques such as polishing can be applied in order to seal macro-pores and minimise the risk of filtering from the internal to the external surface of the vessel (Arnold, 1985; García Rosselló, 2008; Velde and Druc, 1999). Consequently, slips applied in one or both surfaces of the pottery represent, after glazes, the best method for reducing excessive permeability and preventing the chemical attack resulting from the migration of acid and corrosive substances into the ceramic body during its use. Another technical solution for achieving a better cooling of the vessel content - ethnographically documented in places, such as Pakistan (Spataro, 2004) - consists in applying a coat of sand or silt in the internal and external surface of the base of the pottery.

Similar results can be also achieved using substances such as resins on vessel surfaces (Arnold, 1985; Cuomo Di Caprio, 1985; Schiffer, 1990b; Skibo et al., 1997). In this way, organic substances, which are well documented ethnographically in pottery production, tend to have larger crystals than inorganic substances such as minerals (Vidal pers. comm., 2008). Thus, crystals of organic substances penetrate well through the pores of ceramics where they develop and prevent the migration of the content through the vessel walls.

\subsubsection{Lightness}

As ethnographically documented in north-east Ghana (Calvo et al., 2013), lightness is a property of ceramic bodies which consumers may consider when purchasing pottery. In this way, this physical parameter can be useful to address the transport ability of the pottery, a significant aspect that may play a key role especially when the individuals use their own energy to transport the vessels. Thus, it is different to transport light or heavy vessels and to carry them over long distances using different 
transport means such as ships, beasts of burden or people carrying the pottery exclusively by means of their own body.

This parameter has to be considered since, for instance, many people have used jars to collect and store water, moving on foot to the water sources to subsequently transport this resource back to the domestic areas. Moreover, the distribution of the pottery itself can be undertaken on foot across several kilometres, as observed between Konkomba craftswomen in the Northern region of Ghana (Calvo et al., 2013). Therefore, when addressing the portability of the pottery, the lightness of the materials must be taken into account but also the individuals themselves. In this way, this variable, along with other features of the pottery (e.g., size and shape), is strongly related to anthropometric aspects, such as the absolute weight that humans can carry (Arnold, 1999; Balfet, 1984; Rice, 1987).

In this sense, experimental research demonstrated that fabrics which have a high percentage of organic matter, despite having thicker walls, may be up to $34 \%$ lighter than ceramics made with the same amount of mineral temper. The reason is that organic matter has a lighter nature and provides high porosity after its combustion during firing. Thus, fabrics rich in organic matter may be desirable when the individual himself is the one to carry the vessels on foot. The addition of this temper in many societies might correspond to this variable. This fact may explain why these kinds of fabrics are widespread among many societies with high mobility patterns, while their presence is more atypical in sedentary societies (Bollong et al., 1993; Schiffer and Skibo, 1987; Sestier, 2005; Skibo et al., 1989).

\subsection{Functionalism and the Production Process}

Some authors (Rice, 1996; Tite and Kilikoglou, 2002), coming from functionalist and economistic perspectives, suggest that the technological choices made by potters regarding certain materials and techniques have to be related to the requirements of the manufacturing process rather than to the needs associated with the use and function of the pottery. In this explanatory model, the effectiveness of the techniques and materials along the manufacturing processes determines the actions and choices of the potters. Therefore, all the phases of the chaîne opératoire are understood as closely interconnected in physical terms. It is also assumed that potters have a high degree of technical knowledge and are fully aware of the physical effects involved in the choices they make during production. As will be discussed in the examples presented later, the technical benefits of certain materials and techniques in pottery production are present in each of the phases comprising the chaîne opératoire:

a) Clay Procurement

From an ecological and functionalist perspective based on material sciences, the properties of the clays available in the environment are considered to determine the 
techniques and procedures used to produce ceramics (Sinopoli, 1991). The selection of the raw material, then, becomes crucial to fully approach and understand the rest of the phases of the manufacturing process. Thus, it must be accepted that some physical and mechanical properties of the raw materials may influence the several phases of the chaîne opératoire as well as determining the techniques involved in the production process.

Consequently, potters often exploit clay sources that have certain physical characteristics which permit them to manufacture pottery successfully and implement the use of certain tools and techniques. Otherwise, the potters can alter the composition and properties of raw materials. The most efficient clays are those that can be directly used to manufacture vessels without altering the material obtained from the clay pit. The use of coarse clays is advisable to manufacture handmade ceramics, since they are workable and plastic but also contain the amount of non-plastic materials needed to produce the minimum consistency required for modelling vessels, thereby allowing them to continue the subsequent phases of the manufacturing process successfully. This materialist perspective related to the production process may explain why in many societies (see, for instance, Gibson and Woods, 1990; Williams, 1982) clays with these features are often used for long periods of time. In this sense, as previously mentioned, the use of different types of clays sometimes depends on their adaptability to the diverse needs of the production process or the kind of artefact to be produced.

The characteristics of the raw materials partly determine the effort required to develop pottery production. Thus, the time invested to collect the clay and purify and prepare the paste may vary depending on its heterogeneity and texture, as well as on the material selected to temper the paste. Therefore, raw materials selection involves also certain economical and functional benefits and constraints which affect the whole production process. Some kinds of clay may be more accessible and closer to the production areas and be very refined in the source itself. So, the effort required to collect, prepare and homogenise them is significantly reduced compared with other clays which are quite heterogeneous and require a greater time investment to prepare the paste properly. Low labor investment in paste preparation gives rise to heterogeneous ceramic bodies. This irregularity may generate different results in the several stages of the production process due to the compositional variability found in the same vessel. Fabrics with greater homogeneity may indicate that more effort was devoted to grind the clay and to ensure the orderly distribution of the temper, as well as to compact the paste and eliminate the air bubbles present in the clay matrix.

The procurement of coarse-textured clays with the presence of pebbles may require an intense purifying process in order to avoid severe fractures during the subsequent phases of the chaîne opératoire. Moreover, this purification process promotes the elimination of the air bubbles present in the pores of the clay, thus reducing the negative effects which entail their evaporation during firing. Several ethnographic studies argue that the basic purification of the raw material may take 
about 20 or 30 minutes depending on the grain size of the sediment and the needs of the end product (Banning, 2005; Blackman, 1992; Drake, 1972; Gibson and Woods, 1990). In other cases, the forming methods used in pottery production determine the need for very plastic and purified clays which are decanted through levigation in water tanks. Clay levigation may involve, especially when large amounts of raw material have to be processed, the construction of certain infrastructures and higher time investment. However, this purification process is usually undertake exclusively in wheel-thrown vessels, since the centrifugal force used in this modelling technique can damage the potters' hands if the clay has high amounts of coarse and angular non-plastic components.

\section{b) Temper Addition}

Most of the clays which are suitable for pottery production are usually too fine, so that they may have excessive plasticity and problems due to their high water absorption. In these cases, it is necessary to temper the clays with non-plastic materials in order make them workable, thus increasing the time necessary to prepare the paste and achieve the production. From a functional viewpoint, tempers such as sands are added and mixed with the clay with the aim to promote pastes with greater consistency or to enhance their porosity. Thus, this technical action improves certain properties of the paste allowing the proper modelling, drying and firing of the vessels (Drake, 1972; Riley, 1982; Van der Leeuw, 1984; Williams, 1982).

For instance, clays can often be too wet to form the pottery (Cuomo Di Caprio, 1985). In these cases, the addition of dry organic matter to the paste reduces the excess water of the clay thanks to the high hygroscopicity of cellulose fibres (Albero, 2010; Maritan et al., 2006), thus making it possible to achieve an optimum hydration and malleability in the paste as well as a reduction in its plasticity. Hence, technically, the gradual addition of this kind of temper until the paste achieves the adequate malleability makes moist clays immediately usable. As a consequence, the use of this temper promotes the manufacture of pottery production along the whole year and the procurement of different clays with a wider range of humidity.

\section{c) Modelling}

There is an interrelationship between the different kinds of pastes and the forming methods. On the one hand, the physical properties of the paste induce the modelling techniques that can be used to form pottery. In this way, the composition of the paste determines key parameters such as plasticity or the ability of the vessel walls to remain straight. Therefore, the technical gestures that potters perform during the modelling stage are constrained by the possibilities of the paste as well as by its behaviour in subsequent phases of the chaine opératoire. Ultimately, the characteristics of the pastes used to form the vessels determine the shapes that can be modelled, thus influencing the type of end products achieved. On the other hand, the pressure that the potters produce during the kneading and shaping stages can significantly alter the 
arrangement, distribution and orientation of the non-plastic components occurring in the paste. As previously mentioned, the resulting configuration of the paste has consequences in the subsequent behaviour of the pottery, either in the other stages of the manufacturing process, such as drying or firing, or in its use.

Plasticity refers to the ability of a plastic mass to reach and maintain a specific form by the application of energy, while the malleability of the paste is related to its ability to deform without collapsing the form. The malleability required to model a vessel also depends on the forming method used. So, in the coiling method the paste itself must be consistent enough to withstand the weight of the ceramic and allow the vessel walls to stand straight. In this sense, not all the parts of a single vessel require the use of pastes with the same plasticity or are performed using the same modelling techniques. Hence, different parts or accessories of the pottery such as the base or the handles may be made using pastes which are different from the ones used in the manufacture of the ceramic body (Feathers, 2006; García Rosselló, 2008; Schiffer and Skibo, 1987; Steponaitis, 1984; Van As, 1984; West, 1992).

During the modelling process, an intense interaction takes place between the potters and the paste which facilitates learning its properties, as well as the possibilities and constraints of the material regarding its malleability and consistency. Thus, potters can use diverse raw materials or prepare the pastes differently according to the forming methods they use or the form, typology and size of the pottery they produce. For instance, whether the pottery is hand-made or wheel-made or even the thickness of the vessel walls may influence the texture of the paste (Williams, 1982).

In this way, many potter communities prefer to use highly plastic clays because they are easier to model. This choice is made even if these materials are excessively plastic and may generate some problems due to the high stress that takes place in other phases of the chaîne opératoire such as drying and firing. In these phases, the pottery produced with highly plastic and absorbent clays usually experiences a significant loss of volume and often deforms or cracks (Rice, 1987; Schiffer and Skibo, 1987; Stark et al., 2000). Contrary to these fine materials, clays with few phyllosilicates and excessive non-plastic components cannot be used to shape a vessel since they lack the adequate plasticity (Maritan et al., 2007). In these cases, the large amount of coarse inclusions and/or tempers may cause serious problems during the modelling phase, especially when potters join the coils (Martineau et al., 2007).

It is obvious that the use of clays with different compositions potentially affects the ability to model a vessel. In this sense, the selection of certain raw materials and tempers can be influenced by their ability to improve the workability of the paste. Therefore, malleability, plasticity and consistency are parameters that greatly determine certain technological choices involved in the preparation of the ceramic pastes, such as the amount and kind of temper added. Thus, the highest amount of temper that can be added to the clay without excessively reducing the plasticity, malleability and, therefore, the modelling capability of the paste is around $40 \%$ by volume (Krause, 1984; Longacre, 1999; West, 1992). 
The addition of temper breaks the bonds existing between clay particles, increasing the consistency and, therefore, the pressure that can be applied on very fine clays without deforming the vessel walls. Hence, this technical action creates a more workable paste, thus expanding the pottery sizes and shapes that can be potentially modelled. Furthermore, the properties of the paste also determine the time required to model the vessels and the need for different sub-stages along this process, thus influencing the organisation of production. For example, the use of coarse pastes with a high frequency of mineral temper may significantly increase the time needed to produce a vessel, since more time is required to process the paste. Likewise, the modelling of large pots may require several drying stages throughout this phase depending on the properties of the paste and the size of the pottery before the vessel is completely achieved.

Each kind of temper has a different effect on the plasticity of the paste. For instance, grog is a relatively soft material which does not intensely reduce the plasticity compared to other harder materials such as quartz (West, 1992). Meanwhile, calcite provides calcium ions to the paste that act as flocculant and significantly improves the plasticity of certain clays. Therefore, the presence of this mineral expands the number of forming methods available and permits to model a wide range of ceramic shapes and thinner walls (Hoard et al., 1995; Risch and Gómez Gras, 2003; Van As, 1984; West, 1992).

The use of organic matter to temper pottery allows modelling moist clays and obtaining pastes with a high consistency. On the one hand, how long the organic matter was present in the clay itself stimulates the emergence of humic acids formed as a consequence of bacterial action. This process results in a colloidal gel which enhances plasticity in hard clays. On the other hand, the addition of organic matter in highly plastic clays permits the building of the vessels' walls even when they are still moist. This is possible because this kind of paste is very light, thus allowing the uninterrupted and faster construction of the pottery. Moreover, this material provides a fibrous structure to the paste that reduces shrinkage and prevents breakage in the drying process. In this way, the time spent on making pottery is significantly reduced if the paste is tempered with organic matter. Therefore, it is possible to achieve a pottery modelled and fully decorated in less than 30 minutes (London, 1981; Maritan et al., 2006; Morales, 2005; Schiffer and Skibo, 1987; Sestier, 2005; Shepard, 1971; Skibo et al., 1989; West, 1992).

The addition of minerals with prismatic, elongated and angular crystals is considered more appropriate than the use of rounded components to build vessel walls more efficiently and prevent the development of fractures. The reason is that rounded particles have no rough surfaces to which clay minerals can firmly adhere (Gibson and Woods, 1990; Carter, 2002). Nevertheless, pastes with abundant sharp and angular grains are not recommended when the pottery is wheel-thrown. The centrifugal force that characterises this forming method along with the sharp edges of the crystals can cause severe damage to the potter's hands. In contrast, this 
kind of problem should not be expected in hand-made pottery (Hoard et al., 1995; McConaughy, 1987 in Schiffer and Skibo, 1987; Sillar and Tite, 2000; Skibo et al., 1989).

\section{d) Drying}

The multiple actions carried out by potters along the chaîne opératoire also have implications in the drying phase. In this way, some studies on prehistoric ceramics argue that one of the main objectives of the addition of tempers is to provide the paste with a porous microstructure with certain open porosity. Higher porosity allows the evaporation of volatile substances during drying and especially in the initial stages of firing, thus preventing the development of cracks and wall flaking (Gibson and Woods, 1990). Fractures develop during the drying and firing processes as a result of the stress generated when water evaporates faster on the surfaces of the vessels than in the core of the ceramic body. A gradual loss of water is then advisable to minimise stress in the paste. Therefore, an increase in porosity may be relevant to promote a better dehydration of the paste; this could be the reason why certain technical choices were selected in pottery production.

The abundant presence of non-plastic components promotes open-textured clay bodies (Fig. 18.1 and Fig. 18.2) favouring drying in the falling-rate period and the evaporation of water at the beginning of the firing. Hence, the stress that occurs in the paste due to the expansion and contraction of clay minerals is significantly reduced. This process prevents the development of severe fractures, something very usual in highly plastic pastes (Albero, 2010; Khalfi and Blanchart, 1999; LivingstoneSmith, 2007; Martineau et al., 2007; Rice, 1987; Skibo et al., 1989; Worrall, 1975). The addition of temper decreases shrinkage during drying and enhances dehydration of vessel walls, even in seasons or locations where relative humidity is high. Therefore, pottery production can be carried out throughout the whole year (Cuomo Di Caprio, 1985; Gibson and Woods, 1990; Linares et al., 1983).

Experimental tests performed with briquettes tempered with sand indicates that the use of mineral temper decreases the drying time of the paste due to a reduction in the amount of clay present in the mixture. Consequently, the amount of water required to give workability to the paste also decreases (Skibo et al., 1989). Other experiments demonstrate (Albero, 2010; Schiffer and Skibo, 1987; West, 1992) that organic matter favours an open-textured paste with high porosity and a significant rate of macropores and micro-pores (Fig. 18.2). Hence, organic fibres are in contact with the vessel surfaces, thus enhancing the migration of water through the wall during drying and firing. The great weight loss experienced by pastes rich in organic matter is associated with a high hygroscopic capacity. Therefore, the formation of this fibrous structure in the paste prevents the initiation of cracks during the drying stage, improving the resistance of the paste and considerably reducing the capacity of the clay to shrink due to loss water (Sestier, 2005; Skibo et al., 1989; West, 1992). 


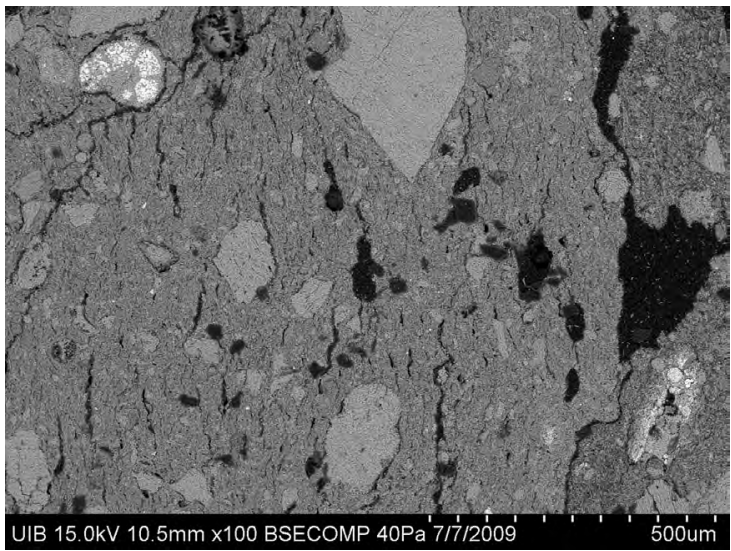

Figure 18.1: Back Scattered Electron Image (SEM-BSEI) showing the porous micro-structure in a paste tempered with spathic calcite crystals.

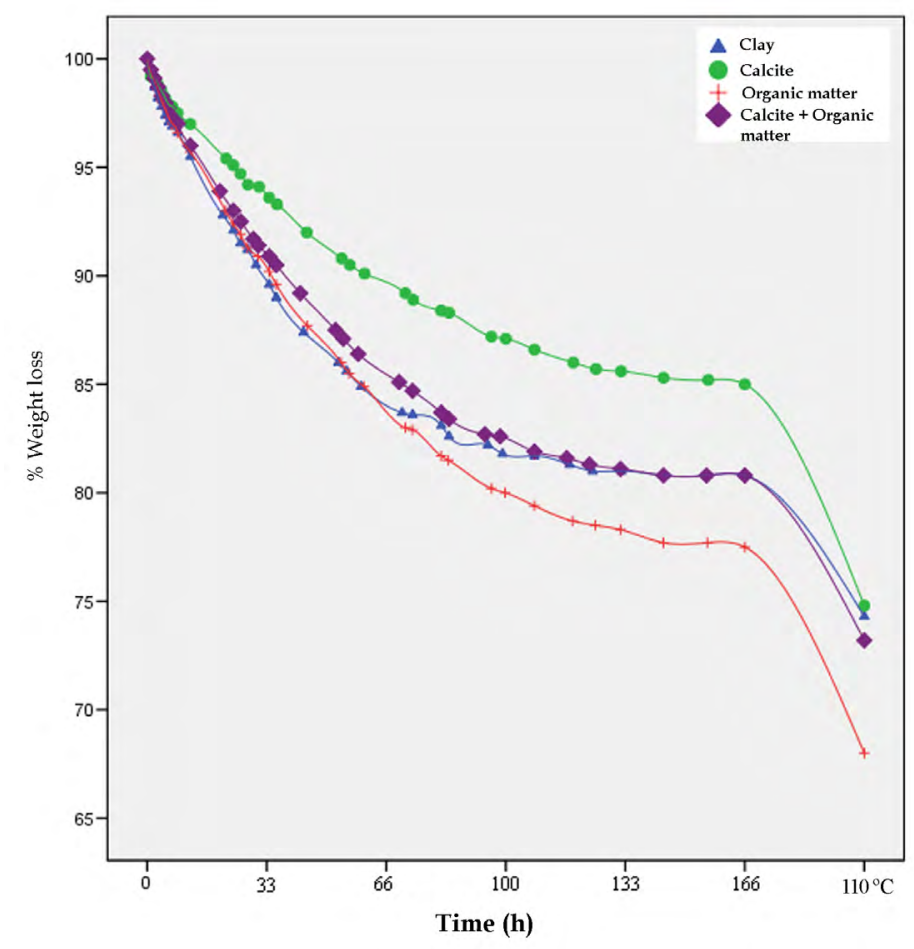

Figure 18.2: Constant rate of drying of a paste observed in a figure that includes the time and rate of loss weight in samples dried at ambient temperature. Drying curves from experimental samples with non-tempered clay, clay tempered with spathic calcite ( $20 \%$ of the volume), clay tempered with organic matter ( $20 \%$ of the volume) and clay tempered with $10 \%$ of the volume of both tempers. 


\section{e) Surface Treatments and Decorations}

In functional terms, surface treatments such as polishing or slips can be applied in order to minimise some negative effects related to the introduction of certain technological choices in pottery production, such as the use of certain tempers or clays. As seen before, slips and burnishing transform the external appearance of the pottery, minimising roughness, covering defects of the walls and homogenising and improving the quality of its surfaces. In addition, these treatments reduce the number of pores that connect then core with the surface of the vessel.

Furthermore, certain surface treatments such as polishing or trimming also promote the dewatering of the paste before firing by the pressure that the non-plastic components generate on the clay. Therefore, thicker inclusions and tempers drive into the clay matrix favouring the migration of water particles to the vessel margins, decreasing the pore water content of the paste and thus reducing drying time. In short, there is a relation between the surface treatments applied and the properties of the fabrics obtained, since these technical actions determine certain attributes of the end products (Banning, 2005; Capel et al., 1982, 1995; Echallier, 1984; Velde and Druc, 1999).

Also some decorative techniques, when intensely performed, homogenise and alter the surface of the vessels, consequently promoting certain physical effects in the paste during drying and firing. In this way, the use of some decorative techniques which were quite common in prehistoric ceramics (e.g., incised pottery) produce more open-textured pastes, thus favouring the evaporation of water and the release of air bubbles from the paste during firing.

\section{f) Firing}

As already seen, firing implies a process where multiple physicochemical changes occur in the ceramic pastes. From a functional perspective, many technological choices undertaken throughout the production process may, in addition to enhancing the behaviour of the materials in the modelling and drying phases, aim at minimising the impact of heating on the paste.

Thus, some studies on prehistoric ceramics state that the abundant temper in a paste is precisely one of the main purposes of creating a porous open-textured ceramic body which allows the evaporation of volatile substances during the earliest stages of firing. In this sense, the coarse texture which provides the addition of temper is advisable in order to avoid the generation of fractures and wall flaking when open firings with fast heating rates are performed (Gibson and Woods, 1990).

Differential thermal expansion of the several components present in the paste must be also considered in the production process, since it can determine the type of clay selected and the kind of temper added to the paste. For instance, grog is composed of fired clay and has a thermal expansion coefficient identical to clay, so it is well suited for tempering pottery (Cuomo Di Caprio, 1985; West, 1992). Furthermore, potters can also remove some components from the paste according 
to their dilatometric behaviour in order to minimise the initiation and propagation of fractures during firing. If the raw materials have abundant inclusions with a high coefficient of thermal expansion, such as quartz, and these cannot be easily removed, the potter may try to reduce their size or frequency in the paste as far as possible through clay grinding, purification or levigation.

Moreover, certain tempers can be added to the paste because of their effects during firing. For example, the use of organic matter by sedentary potter communities was associated with the fact that this temper promotes a relatively uniform firing and reduces the amount of fuel needed in this process. The use of pastes rich in organic matter is especially useful in environments where the potter does not effectively control many of the variables involved in firing, such as atmospheric agents (e.g., wind, humidity, etc.), as often occurs when open-firings are used to fire the vessels (Morales, 2005; Skibo et al., 1989).

There are also interpretations in which technical knowledge is the main factor determining the firing procedure. A good example of such explanations relates to the different skills and technical choices which potters are able to develop in order to address problems arising from the use of very calcareous pastes. In this way, there are several technical options they can undertake in order to avoid or reduce the negative effects that entail the decomposition of calcium carbonate during the firing. Examples of these technical solutions are, among others, the use of reducing firing atmospheres (Hoard et al., 1995; Letsch and Noll, 1983; Maritan et al., 2006), the application of salt or sea water to prepare the pastes (Arnold, 1985; Hoard et al., 1995; Rye, 1976, 1981) or soaking the pottery in water just after the firing (Hoard et al., 1995; Morales, 2005). All these technical solutions - such as the addition of certain materials to the paste (e.g., salt, etc.) or the use of certain firing procedures (e.g., low firing temperatures, reducing atmospheres, etc.) and techniques (e.g., soaking the pottery) - are understood as choices that are essential to carry out pottery production and therefore, this is the main reason why they are carried out.

Furthermore, the use of different kinds of fuel may be also associated with technical aspects, such as the control of the maximum temperature, its duration and the atmosphere during firing. This technical use is possible because different fuels have different heat capacities and specific flames, both of which are parameters that depend not only on the type of material, but also on its moisture content (Cuomo Di Caprio, 1985; Morales, 2005). In this way, some fuels reach temperatures of $750^{\circ} \mathrm{C}$ after only a few minutes, so that after some 10 minutes of firing, the vessels can be removed from the structure. By contrast, fuels such as dung provide, as demonstrated experimentally (Palamarczuk, 2004), temperatures not higher than $500^{\circ}-700^{\circ} \mathrm{C}$. Other materials such as bones do not allow increasing the temperature, but permit it to be maintained for longer (Yravedra et al., 2005). In this sense, the use of different fuels or their combination can be related to different types of ceramics. For instance, there are some fuels that are technically unsuitable to fire large storage vessels. 
Finally the use of certain firing structures, such as kilns, is closely associated with the potter's desire to strictly control certain technical variables involved in the firing process. Thus, these kinds of structures allow potters to achieve high temperatures, promote a more efficient heat flow inside the structure and control the firing atmosphere. In this sense, some authors (e.g., Sinopoli, 1991) also state that the firing procedure may determine the kind of fuel to be used.

\subsection{Functionalism and Ceramic Building Materials}

From a functionalist perspective mud building materials and pottery respond to different requirements. Thus, materials that lack plasticity and in consequence cannot be directly used in pottery production, where at least $35 \%$ of clay minerals are required (Arnold, 1993), may be suitable to act as building materials. In the production of clay building materials it is neither necessary nor advisable to use sediments rich in the clay fraction, but preferably sandy loam or silty loam soils, as these provide more stability to the structures and absorb less moisture (Morales, 2005; Morales et al., 1985; Rodríguez and Saroza, 2006; Sánchez García, 1999). Building materials must resist the disintegrating action of atmospheric agents and have mechanical strength. The causes that influence their effectiveness are resistance to moisture, frostbite, atmospheric activity, compaction and mechanical shock as well as possess a certain bending capacity (Morales, 2005).

In this sense, there can be a discriminating strategy in the management of the raw materials available in the environment depending on the kind of artefact to be manufactured. For instance, as currently seen in the ceramic industry, available resources that are excessively calcareous are used to manufacture ceramic filler blocks (Delgado et al., 2007), porous tiles (Lacasa et al., 2000) and other building materials (Strazzera et al., 1997). Similarly, in prehistoric times highly calcareous mud and materials with low plasticity were used as building materials, for instance for waterproofing structures (Albero and García Amengual, 2010; Kovács et al., 2009; Starnini and Szakmány, 2009). Nevertheless, this distinction in the raw materials used in the production of pottery and building materials is not universal. In some cases, the raw materials used for both activities may be the same, although the pastes associated with each type of product can be differentially prepared (Sofaer, 2006).

Many ethnoarchaeological (Barley, 1994; Vaughn and Neff, 2004) and archaeometric (Albero and García Amengual, 2010; Bonzon, 2003; Di Pierro, 2003; Kovács et al., 2009; Martineau, 2007; Starnini and Szakmány, 2009; Taubald, 2009) studies demonstrate that many communities have selected different raw materials to produce building materials and pottery since the Neolithic. This complex management of the raw materials shows that the humans perceived and distinguished among different types of clay deposits with different properties and made preferential choice of them depending on their needs. 
Besides the procurement of different raw materials, building materials are also often processed differently than the pottery. In this way, as observed for example in the current production of adobes in Cahuachi (Peru) (Vaughn and Neff, 2004) or in the Iron Age in Mallorca (Albero, 2011a), building materials are rarely purified or levigated, but used as obtained from the source. Firstly, decantation requires a high time investment due to the large amounts of mud that usually needs to be processed. Secondly, the purification of mud raw materials for building purposes is usually harmful, since it significantly increases their plasticity. In this way, the use of highly plastic clays or excessively levigated materials endangers the effectiveness and stability of the building material and, therefore, the safety of the individuals who inhabit in the structures.

Therefore, in these kinds of mud materials, only organic and mineral impurities that are macroscopically identifiable are expected to be removed. Moreover, the raw materials commonly selected to produce bricks and roof waterproofing structures are already coarse textured and have abundant sands as well as some pebbles. This is the reason why they usually do not receive complementary treatments that alter their composition and texture, such as the addition of tempers. Moreover, it is common to find inclusions of plants (Fig. 18.3 A) and animals such as gastropods in adobe bricks (Sánchez García, 1999; Albero, 2011a). These findings indicate that the mud was not purified and was used as obtained from the source.

The clay materials used for multiple architectural purposes are normally procured, prepared and applied quickly and easily. In addition, the raw material can often be obtained and prepared with little effort near the architectural structures themselves. Given the limited preparation these materials need, the individuals who manage these materials do not require highly specialised skills. However, the use of mud to build waterproof structures, usually applied over a wooden frame, has some constraints derived from the poor mechanical strength of this material and its limited ability to insulate the structure from the outside. In addition, these kinds of structures must be regularly maintained, repaired and replaced due to the high risk of fire, the growth of parasites, the decomposition of the wood because of moisture retention or the effects of other atmospheric agents (Sánchez García, 1999).

The addition of temper is documented in some cases (e.g., Albero and García Amengual, 2010) where the closest clay source available to produce the waterproofing material is too plastic and fine-textured, with just a very small amount of sand and pebbles. As already explained, highly plastic and fine-textured clays are usually very absorbent and have more capacity to increase or decrease in volume. Once the clay reaches its maximum rate of water absorption, the liquid starts to filter through the structure and the application losses its physical integrity.

Since these kinds of plastic materials undergo dilatometric changes when hydrated and dehydrated, they generate significant loads that cause mechanical stress in the architectural structures and endanger the integrity of the spaces inhabited. In this sense, the addition of temper to the raw material improves its functional 
requirements. Hence, the addition of temper such as organic matter to highly plastic building raw materials is advisable for several reasons (Rodríguez and Saroza, 2006; Sestier et al., 2005).

- It allows the immediate use of the material even when it is too wet.

- It increases the water absorption capacity of the paste, preventing the clay to be excessively hydrated.

- It decreases the plasticity of the clay while slightly increasing its tensile strength. Its addition reduces, therefore, the stress the architectural structure undergoes.

- It reduces shrinkage during drying and distributes the stress resulting from this process along the fibrous material structure.

- It accelerates the drying time of waterproof structures and improves drainage by removing the water through the organic fibres.

- It makes waterproof roofs lighter, so that the structure withstands less weight and, therefore, the risk of collapse is reduced.

It is therefore not surprising that the use of organic matter to temper mud building materials (Fig. 18.3 B) is a quite widespread technological choice. For instance, its use is especially common to make wattle-and-daub walls by layers (Albero and García Amengual, 2010; Capelli et al., 2006; Kovács et al., 2009; Sánchez García, 1999; Sestier et al., 2005; Sofaer, 2006; Starnini and Szakmány, 2009). In these cases, the identification of the plants used as temper can be done through the creation of experimental reference collection. Moreover, in contrast to the organic matter present in pottery, its identification can be also made through the analysis of the phytoliths and pollen occurring in these artefacts. Since building materials are usually unfired, the application of the latter techniques is plausible in these cases because pollen and phytoliths are usually destroyed at temperatures above $250^{\circ} \mathrm{C}$. Therefore, these components are expected to be well preserved in the fabric.

The plasticity and malleability that building materials require to exercise their function is completely different than in the case of pottery, since clay building materials usually do not involve complex forming methods. Thus, waterproof roofs or mud walls are just constructed directly by applying the mud onto the structure, while the bricks are modelled by means of moulds of specific dimensions into which the clay is compacted. However, the requirements stated for building materials may change if other kinds of clay artefacts with other functions are considered. For instance, loom weights can be made using clays with a significant quantity of clay minerals and, therefore, with high plasticity. Thus, the clay loom weights observed in some studies (Albero and Garcia Amengual, 2010; Starnini and Szakmány, 2009) are characterized by fabrics with high compactness, low porosity and greater density that benefit their function as elements to generate download tension. Additionally, loom weights can have specific morphological and metric characteristics, thus requiring raw material with a minimum of consistency and plasticity in order to shape artefacts that follow certain typological canons. 
A
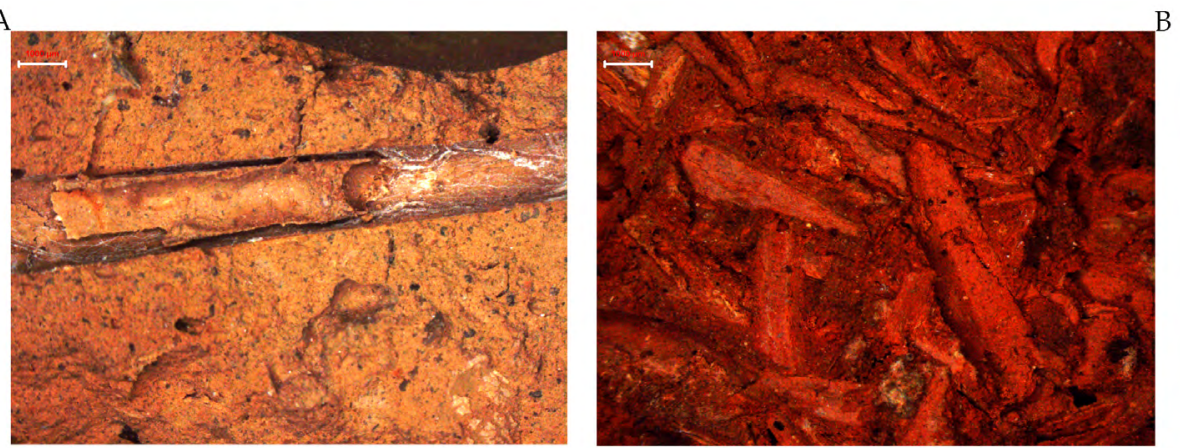

Figure 18.3: Microphotographs showing A) a huge organic matter fragment naturally occurring in the clay used to made an adobe brick (Image width $=11.2 \mathrm{~mm}$ ). B) Organic matter added as temper in a building material used to waterproof a roof (Image width $=11.6 \mathrm{~mm}$ ).

\begin{tabular}{|l|l|l|l|l|l|l|l|l|l|l|}
\cline { 2 - 10 } \multicolumn{1}{l|}{} & F1 & F2 & F3 & F4 & F5 & F6 & F7 & F8 & F9 & F10 \\
\hline Thermal effectiveness & & & & & & & & & & \\
\hline Thermal shock resistance & & & & & & & & & & \\
\hline Abrasion resistance & & & & & & & & & & \\
\hline Cooling effectiveness & & & & & & & & & & \\
\hline Permeability & & & & & & & & & & \\
\hline Impact resistance & & & & & & & & & & \\
\hline Strength & & & & & & & & & & \\
\hline Lightness & & & & & & & & & & \\
\hline Time Investment
\end{tabular}

Figure 18.4: Multifactor performance matrix comprising physical properties of different pottery fabrics.

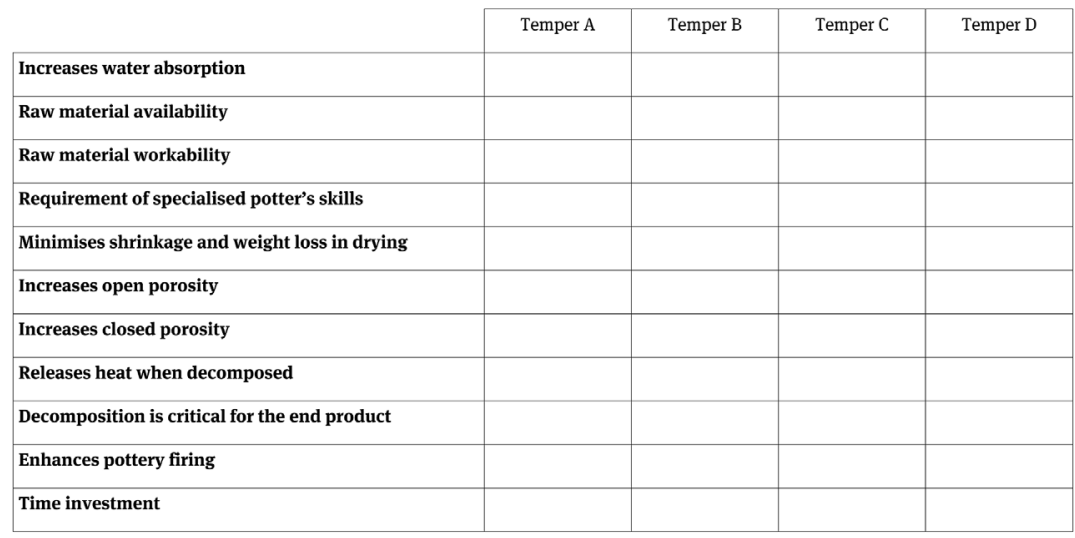

Figure 18.5: Multifactor performance matrix comprising some physical properties that imply the use of different tempers in pottery production. 


\subsection{Fabrics and Typologies: Production Processes, Variability and Function}

All the parameters addressed above regarding the role of the properties of pastes and fabrics in the production and use of ceramics can transcend the study of the materials themselves. In this way, the archaeometric information obtained can be related to the typology of the vessels with the aim of incorporating also morphological variables in the analysis of archaeological ceramics. Thus, different approaches that establish relationships between the fabrics and types appearing in the ceramic assemblages or taxonomic categories that make up the archaeological record have been postulated since the 1980s 22 (Banning, 2005; Cuomo Di Caprio, 1985; Gibson and Woods, 1990). Typological and archaeometrical studies supplement each other and constitute a framework in which several dimensions of the pottery can be addressed. The purpose of this kind of research is to eventually explain the complexity underlying the features of the ceramics and obtain information as complete as possible regarding their life cycle.

The combination of different analytical approaches addressing common issues in the technological study of the artefacts more efficiently define the aspects to be taken into account when considering the role of pottery in society. While the different kinds of analysis performed on archaeological ceramics (e.g., typology, fabrics, absorbed residues, etc.) have to be undertaken separately, the multiple fields of study are ultimately interconnected in the object itself, where all the features recorded appear simultaneously. Therefore, these multiproxy approaches lead to the formulation of more robust and complex hypotheses about the significance of certain technological choices and to assess the relevance of the changes which took place in the ceramic production in a broad sense.

The merging of the archaeometric analysis of pottery fabrics with the study of the typology of vessels facilitates the identification of the technological choices made for the manufacture of artefacts with certain physical properties. In this way, since each technology has a number of priorities and preferences which are reflected in the characteristics of the artefacts, it is possible to relate some technological choices to certain lifestyles as well as specific activities (Capel et al., 1982; Hally, 1986; Sánchez and Aranda, 2005; Schiffer and Skibo, 1987; Spataro, 2002; Tite et al., 2001).

One of the main constraints that often arises when trying to relate prehistoric pottery fabrics to typologies is associated with the small number of vessels suitable

22 There are many studies which apply this approach for the study of ceramics (e.g., Capel et al., 1995; Colomer, 2005; Clop, 2007; Cordero et al., 2006; Freestone and Rigby, 1982; Galván, 1995; García Heras et al., 2001; Hally, 1986; Morris, 1982; Odriozola et al., 2009a; Renfrew, 1977; Risquez and Hornos, 1999; Seva and Almiñana, 1996; Spataro, 2003, 2006; Stepoinatis, 1984; Stilborg, 2003; Turbanti, 2004; Van As, 1984; Woods, 1986). 
for analysis, which necessarily limits the scope of such approaches. Thus, three main requirements must be accomplished. First, it is essential to study ceramic assemblages that are well contextualized in spatial and chronological terms. Second, the vessels analysed must have a fully reassembled profile or at least preserve a considerable part (Rice, 1996). This requirement is especially important in hand-made prehistoric pottery, since there is often a low typological standardisation and the whole shape of the vessels cannot be deduced only from small fragments. Third, it is necessary to have the chance to perform archaeometric analysis on the vessels.

The combined study of pottery fabrics and shapes is performed with a multiple purpose in mind:

\section{a) Analysis of the Manufacturing Process}

As already seen, the materials used in pottery production should meet certain requirements of the manufacturing process, some of which are related to the form and size of the vessels to be modelled. In this way, the properties of some raw materials and pastes may be restricted to the manufacture of small-sized vessels where fractures are not only less severe and visible, but also easier to fix. Hence, if large vessels are modelled with these raw materials they will probably break. By contrast, other coarser clays or pastes are more firm and consistent, thus favouring the modelling of all kinds of vessels without any risk of fracture (Arnold, 2000). In this way, large storage vessels require pastes with abundant non-plastic components in order to make the vessel walls remain standing during the modelling and firing processes (Velde and Druc, 1999). This division between fine-textured pastes associated with small and mediumsized vessels and coarse-textured pastes related to large pottery is documented, for instance, in the Late Iron Age in Mallorca (Albero, 2011a). Moreover, it is also ethnographically observed in Quinchamalí and Pilén (Chile), where the kind of pastes used in pottery production is related to the size of the vessel to be manufactured, explaining the variability observed in the pastes (García Rosselló, 2008).

The study of the relationships existing between fabrics and types permits us to identify whether the technological choices and the fabric features correlate with morphometric parameters. Moreover, it is also possible to consider how the size and shape of the pottery could determine the manufacturing process of pastes and fabrics. In this way, it can be assessed, for instance, the morphometric characteristics of pottery assemblages made from raw materials of the same provenance or similar physical properties. Also, the subsequent technical actions performed on the raw materials regarding the type of product to be manufactured can be assessed.

The type of pottery produced as well as its form and size, can thus determine the manufacturing process of pastes to obtain fabrics with certain properties. Consequently, the simultaneous consideration of the technology of fabrics and the typology of vessels can help sort, understand and explain certain technical actions documented in the chaîne opératoire. In this way, the relation between textural, mineralogical or chemical attributes and morphological and metric characteristics 
of the pottery can be established in the taxonomic systems normally used by archaeologists.

This analytical strategy reveals the relations between the forms modelled and the different fabrics recorded. For instance, we can record whether the same paste recipe is used to manufacture a wide range of vessels associated with different types. This situation would indicate that there is neither a morphometric nor functional specialisation regarding the technological choices involved in pottery production. However, the use of a specific fabric to achieve multiple forms evidences that the material has broad possibilities for modelling several types of vessels. In contrast, the use of many pastes to model the same type indicates, among other aspects, that a specific shape is easy to achieve using a wide range of materials and technical choices.

\section{b) Functional Analysis}

Although universal models cannot be established, typology is a classification system that also relates to pottery function. A clear relation between the function and the size of the vessels is observed, for instance, when they are used for measuring the amounts of a wide variety of products such as grain or liquids, as well as to estimate portions of food, drinks, etc.

As previously stated with pastes and fabrics, the shape and size of the pottery can also be enhanced in order to maximise the features of the end product according to specific functions (Albero et al., forthcoming). For instance, as already seen, the use of certain shapes allows improving thermal shock resistance and heat effectiveness in cooking pots (Hein et al., 2009). In this way, the use of morphologies in which the base and the body form a continuous curve, as in hemispherical or globular vessels, can efficiently reduce the risk of fractures arising from dilatometric changes caused as a result of the direct exposure of the pottery to the fire. In contrast, angular junction points in the ceramic body are more susceptible to breakage, since they concentrate much of the stress occurring in the pottery (Gibson and Woods, 1990). As a consequence, this type of pottery is more likely to fracture at the junction points as a result of thermal shock. Likewise, resistance to impact is also determined by the morphology of the vessels. Thus, a pottery with angular junction points is less resistant than others with continuous curves. In this sense, junction points between different parts of the vessel are weak areas susceptible to be fractured as a consequence of impacts (Schiffer and Skibo, 1987; Skibo et al., 1989).

An analytical strategy linking fabric and typology may allow a better approximation of the functionality of the pottery, since the size, shape and fabric of the vessel can be determined by its function. In this sense, the combination of the typological analysis with other parameters is a suitable method to approximate the function of the vessels not exclusively with typological viewpoints, but also with technological ones. Therefore, it is possible to approach, for instance, the possible functional relation existing between the features of the fabrics or the forming methods and the typology of the pots manufactured (García Rosselló and Quintana, 2003). 
Ethnographical studies show how potters often select their raw materials depending on the shape, size or function of the ceramics they produce, three aspects that can be closely interrelated (Velde and Druc, 1999). For example, in Chinautla, potters collect yellow clays to produce storage vessels, while they prefer white clays to manufacture other types of pottery, such as those used for water transport. In Tikul (Yucatan, Mexico), potters carefully select the clays used to form large vessels for storing liquids (Arnold, 2000). In Pòrtol (Mallorca, Spain) potters select red or ochre clays depending on the function of the vessels (Albero and Puerta, 2011). In short, this differential selection of raw materials which affects the chemical, mineralogical and textural composition of pastes and fabrics may be in close connection with the different types of vessels manufactured. In these cases typological parameters may explain the compositional variability of the end products.

Therefore, an analytical strategy combining the composition of the pottery and its typology not only informs about the manufacturing process and allows a better classification of ceramic assemblages, it also identifies whether there are certain technofunctional concerns involved in the way typologically similar objects were produced in order to enhance their use in specific activities. In other words, this strategy allows us to assess whether the potters perform specialised behaviours with the aim of generating both fabrics and types more efficient to accomplish specific functions.

The study of vessels' functionality by these kinds of approximations can be based on a number of basic criteria (García Rosselló and Quintana, 2003):

- The comparative study of the fabrics of vessels that have similar morphometric characteristics, which allows assing pottery that may respond to similar functional criteria.

- The typological study of pottery of the same or similar fabric and which therefore has similar physical properties. This demonstrates the morphological features of vessels made following specific technological choices that may also respond to a functional rationale.

- The study of ceramic materials from archaeological sites with well-established functions and chronologies. This strategy permits making comparisons between artefact features in synchronic terms as well as in specific functional contexts. This strategy also includes the area of activity in which the pottery is located and, therefore, allows us to accomplish a deeper study of the functional complexity involved in the processes of production, use and deposition.

- The study of materials related to well-established stratigraphic contexts. This requirement is undertaken in order to make sure that the ceramic samples analysed are related to the same chronological period and belong to the same cultural group.

- The study of vessels that have a complete profile with the objective to avoid establishing typological sequences and interpretations from highly fragmentary materials. In this sense, the better preserved the shape of the vessels, the higher the functional information they provide. 
While certain correspondence between form, fabric and function can be theoretically suggested, in practice this approach has significant constraints. In this way, technological choices appear to be often more related to different ways of making pottery than to a techno-functional specialisation of the vessels. Perhaps the best example of this phenomena is the widespread replacement in many societies, for instance in the Middle Bronze Age in the Balearic Islands (Guerrero et al., 2007), of hemispherical bases for flat bases. As we have seen, the latter are less efficient to produce cooking pottery with more heat effectiveness and impact strength and, ultimately, have lesser durability. This quite common substitution of pottery forms has been related to a lack of technical knowledge of the potters regarding the thermal and mechanical effects involved in the use of certain types of bases (Gibson and Woods, 1990).

In other cases, as also seen in the Balearic Islands between 1500-500 BC (Albero, 2011a), a single fabric was almost exclusively used in the production of a wide range of types. Thus, there are no differences in the technological choices regarding the form, context or chronology of the vessels. Hence, pottery of diverse typology and chronology found in different types of archaeological sites can be very similar in their chemical, mineralogical and even textural composition ${ }^{23}$. It is obvious that there is no functional enhancement in these situations, since pottery objects with different shapes and size have similar physical properties. Neither the function nor the context seems to determine the characteristics of the ceramics. Furthermore, although there are refractory clays in the nearby territory, they were not exploited to produce cooking pots.

This same phenomenon is ethnographically observed among Konkomba and Kusasi potters from north-east Ghana (Albero et al., 2013; Calvo et al., 2013) or the potters from Faro in Cameroon (Livingstone-Smith, 2000). There are also potters from Cuzco (Sillar, 1997) and Ancash (Peru) who use the same paste to produce all kinds of artefacts, although in the latter case the effort invested in preparing the paste and its texture depends on the type of pottery manufactured (Druc, 1996). In contrast, potter communities from Tuxtla (Mexico) use different raw materials but they prepare them in a way that finally results in coarse textures for all the pottery typologies of the region (Pool, 2000). Finally, there are regions such as Chinatula and Sacojito (Guatemala) where potters prefer the use of white clays for pottery production, even though they also have red clays of higher quality at hand (Arnold, 2000).

Particular technological choices can be made in order to define the function of the vessels in situations where the same shapes and fabrics are used for a wide range of contents and activities. An ethnographically documented example is the use of

23 There are many other archaeological examples that evidence the use of the same or very similar fabrics in the production of the whole ceramic repertoire in which the main differences observed among the different types are basically textural (e.g., Clop, 2007; Gasull and Lull, 1984; Gherdán and Horváth, 2009; Gliozzo et al., 2008; Heidke and Miksa, 2000; Jorge et al., 2009; Kretier et al., 2007; Odriozola et al., 2009a, b; Ortega et al., 2005; Spataro, 2002, 2006). 
vessels with surfaces of different colour depending on the kind of content. Therefore, a certain pottery type fired under an oxidising atmosphere is used for a particular purpose, while the same type of vessel fired in reducing conditions is used in the management of other kind of content (Barley, 1994; Sillar, 2000). Hence, it is possible to see how vessel functionality also influences certain aspects of the firing process, such as firing atmosphere. Furthermore, the typology of the vessels can be also used to differentiate diverse kinds of contents stored in very similar forms. For instance, the Kabyle people living in the Maghreb use inflection points located at different parts of their globular vessels to distinguish pottery related to different functions (Balfet, 1984).

Sometimes more evident connections between fabrics and shapes can be observed regarding parameters such as the chronology and/or the depositional context of the vessels. As will be fully addressed in the next chapter, ceramic technology and its relationship with certain fabrics, types, contexts and chronologies has to be linked to aspects such as the social organisation of production, technological traditions, habitus, learning processes, tastes and lifestyles. Therefore, rather than promoting an essentialist viewpoint in which ancient potters developed highly specialised conscious behaviours in order to maximise the functionality of their vessels, we have to consider that all these aspects may also have determined specific ways of understanding and conceptualising pottery assemblages (vide infra).

In this sense, in other cases, as in the Late Iron Age in Mallorca (Albero, 2011a), different ways of making pottery are simultaneously present. However, they do not seem to obey functional aspects but rather to the chronology and the type of settlement in which the ceramics were deposited. Thus, the fabrics of the vessels are just related by the context in which they were used and deposited. Although the vessels relate to the same period and are very similar in size and shape they were produced using different chaînes opératoires.

Therefore, it is not often possible to define clear connections between form, technology and function beyond the specific analysis of each pottery within a given productive framework and context of use. Beyond general tendencies, it is clear that many potters have not developed a clear functional specialisation in the manufacture of more efficient fabrics related to vessels with specific morphometric features adapted to certain activities. On the contrary, the ceramic record often seems to respond to other phenomena related to multiplicity, lack of specialization, redundancy and polyfunctionality. Thus, the compositional studies of ceramics may be quite limited in most cases to address the functionality of ancient vessels, confirming the need to develop more sophisticated approaches. These approximations must undoubtedly include the morphometric study of ceramics, the identification of absorbed residues and the analysis of the contexts in which the vessels were used and deposited.

It can be concluded, then, that the fabrics and pastes from different periods and societies often do not clearly obey functional criteria. However, as some authors have pointed out (Hodder, 1991; Pfaffenberger, 1992), the technological features of 
the pottery made and used by past societies are usually interpreted on the basis of functionalist approaches and categories in which western and modern perspectives prevail. This practical and uncritical viewpoint in which material culture is understood in terms of techno-functional optimisation is subjective, hypothetical and constructed. This explains why this approach is often unsuccessful when addressing the significance and the meaning of the materiality of other cultures and why in many cases the functional specialisation of the vessels does not seem to be important in pottery production. Finally, these arguments demonstrate that the concept of function is contingent and must be understood only within specific cultural contexts.

In this scenario everything indicates that the explanations are much more complex and that pottery features are strongly related to the different ways of producing ceramics associated with different cultural contexts. As noted Gosselain et al. (1996), there is enough evidence to suggest that the technological choices involved, for instance, in the clay procurement and the processing of materials are best explained in cultural rather than in functional terms. Therefore, when there is a weak correlation between typology, fabric and functionality, it is usually considered that other non-functional parameters determine the characteristics of the ceramics. In these cases, it is supposed that environmental, cultural or social factors more decisively influence vessel features and their significance (Albero, 2008; LivingstoneSmith, 2000; West, 1992).

In any case, it seems that the form, size and function of the vessels may determine, at least in some cases, certain basic characteristics and properties of the fabrics, as well as the strategy used by the potters for selecting and preparing their raw materials. As noted above, a basic classification of the ceramic record observed in many traditional potter communities consists, for instance, in distinguishing between fine and coarsetextured fabrics. In this sense, I. Druc (1996) emphasises the need to pay special attention to the texture of the fabrics in order to address the possible functional adaptation of the ceramics when their chemical and mineralogical composition is quite similar. Moreover, other authors (Gherdán and Kovath, 2009) suggest that fabrics having more than $10 \%$ of temper are most likely evidence of the intentional behaviour of potters aiming at meeting certain functional parameters, as from this amount of temper certain physical properties of the materials are significantly altered.

\section{c) Variability Analysis}

One key objective in many studies of ceramic technology consists in approaching the variability and the level of standardisation of the production, for example through the analysis of fabrics. If this analysis of the technological variability of the fabrics is undertaken considering also typological diversity, the approach to standardisation of the ceramic record is significantly enhanced. Thus, this research strategy provides a more consistent basis to explain certain technological parameters, such as potter's skills.

In this sense, without enlarging on the topic, typology can be considered a methodology developed for the management and classification of the archaeological 
record. In this way, this procedure creates broad categories of artefacts related to specific spatial, chronological or cultural frameworks that once established can be compared with others (Aranda, 2001; Bate, 1998; Kililikoglou and Vekinis, 2002; Lumbreras, 1987; Van As, 1984). Therefore, as happens with fabrics in the compositional analysis of pottery, typological variability should not be understood as a purely taxonomic or classificatory system, but one used to make interpretations going beyond exclusively functionalist concerns (Albero et al., forthcoming).

The analysis of variability can document similarities or differences in both fabrics and types regarding certain technological choices that respond to particular ways of organising production. Therefore, homologies between the typological variability of the vessels and their manufacturing process can be detected. It is possible to determine, for instance, if certain fabrics are related only to certain pottery types and evaluate the correspondence between marginal types and fabrics that could indicate minority technological choices.

Furthermore, pottery variability may depend on the life expectancy of the vessel, a parameter closely related to its function, size, form and fabric (Mills, 1989; Shott, 1996). From a functionalist perspective, the type of archaeological site and the activities performed in it determines the kind and amount of pottery present as well as the way it was used. Vessel management and their spatial distribution determine their frequency of use, life expectancy and need for replacement. In this way, the use life of the vessels may depend on their spatial mobility and function. The use life determines the demand that users make of certain types of vessels, thus, affecting the production of potters, who, in turn, will more intensely manufacture the products that society demands.

This process suggests that some types are produced more intensely than others in time and space. Therefore, potters manufacture certain vessels more regularly and put in practice certain specific technological actions more often than others. In this way, B. Mills (1989) recorded several ethnographical case studies where serving wares and cooking pots have an intense daily use and a short use life that promotes a high rate of replacement. In consequence, these types of vessels are more regularly produced, being more likely to be replicated. In this context of continuous production the variations between one pottery and another are reduced, since the potters have fewer possibilities to live new experiences in time. In contrast, other typologies such as large storage jars are less mobile and are located in restricted spaces. Sometimes, as we observed in north-east Ghana, this pottery is even attached to the floor. Therefore, these kinds of vessels usually have a long use life and consequently are less frequently made. Thus, potters have more chances to be exposed to new experiences between the production of one vessel and another and, in consequence, are more likely to introduce variations in their technological choices.

Therefore, attention should be paid to how the use and deposition contexts relates to pottery, since the kind of settlement and the activities performed may determine divergences in the technological features of ceramics (Aranda, 2001; Calvo 
et al., 2004b; Cordero et al., 2006; Polvorinos et al., 2005; Roux, 2011). Associative and comparative analyses interrelating the amount and types of artefacts present within the same and diverse stratigraphic units or areas of a given site can provide information about the functionality of the context and, therefore, of the ceramics found. Similarly, the study of the functions and the properties of pots may determine which specific activities were developed in certain areas of the settlements. In this sense, it is crucial to contemplate the functional traits of the vessels and the spaces where they are found. Both aspects are closely interrelated and their combined study strengthens the conclusions obtained from both perspectives independently (Calvo, 2007; Capel et al., 1982; Clark, 2007; Stilborg, 2003; Sullivan, 1989; Tite et al., 2001).

\subsection{Criticism to Science-based Material Approach}

Functionalist interpretations give an essential role to the physical properties of the vessels, thus emphasising materialistic viewpoints over idealistic perspectives. As a consequence, the social context is considered in this trend as being circumstantial and anecdotic and is left in the background. Although functionalist approaches sometimes opportunistically address structural, social and cultural issues, the fact is that these kinds of concerns are considered only when it is not possible to successfully explain the data by means of biological and practical interpretative frameworks (Hodder, 1991). One example of such approaches is related to the use of grog as temper in cooking pottery. It is noted that no significant technical benefit is detected in the vessels regarding this function the despite the fact that this technological choice is documented in cooking wares of many societies worldwide. Therefore, it should be thought that cultural rather than practical criteria determine this technological choice and give it significance (Rye, 1976; West, 1992).

Although it is sometimes admitted (e.g., Tite and Kilikoglou, 2002) that certain technological choices may not strictly respond to practical purposes but rather to social, ideological or political reasons, greater emphasis is paid to materialistic perspectives. Hence, aspects that do not fit in the very material dimension of the objects are broadly classified as cultural or ideological. Hence, explanations do not focus on the phenomena underlying these technological choices since they are foreign to the scientificist and materialistic background that characterises this perspective. Furthermore, the symbolic dimension of the pottery is rejected as they considered that it does not play any important function during the life cycle of ceramics nor does it determine the same existence of the vessels.

It is true that potters sometimes make, although maybe unconsciously, technological choices that seem to make sense in terms of functional efficiency. It is also obvious that pottery is produced to be used in many and varied activities and, as noted by $\mathrm{P}$. Arthur (2007), it is not possible to assess the meaning and significance of the ceramics properly if they are not understood within a range of specific uses and daily practices. 
In this sense, functional aspects involved in both the production and use processes play an important role when defining the meaning given to the vessels since their symbolic significance derives from how the objects are produced and used (Hodder, 1991).

However, to consider that the only purpose of ancient potters was provide certain physical and utilitarian characteristics to their pottery is both a fallacy and a simplification of the concerns that must be addressed in archaeology. In short, it runs the risk of giving a disproportionate role to one aspect of pottery production that could be purely epiphenomenal (Rice, 1990, 1996). The fact that many potters have chosen counterproductive choices in terms of efficiency demonstrates the low epistemological value of these perspectives in many ancient and current societies.

Therefore, multiple objections have been made to functionalistic theoretical trends focused on material sciences and the physical properties of the artefacts as a means to interpret the technological features of the record. This approach places great importance on the conscious behaviours of potters in their production and technological choices in terms that could be called "methodological individualism" (Dobres and Robb, 2000).

As mentioned, behavioural perspectives try to establish connections between the use of specific materials and certain functions in terms of efficiency by means of experimental tests. However, they also recognise that, although certain relations can be acknowledged from modern science, it is not possible to discover whether ancient potters perceived and were aware of the complex connections existing between technical actions, materials and physical properties. Thus, potters could not have understood all the technical and scientific standards governing a technology (Schiffer and Skibo, 1987).

An example of how the technological processes involved in the manufacture of ceramics are not exempt from ambiguity from an emic perspective can be observed in the behaviour of the current potters from Crete. It has been ethnographically documented (Hein et al., 2004a) that there is no consensus among the potters of this island regarding the reasons that lead them to mix red clays with calcareous clays. Potters from Thraspana note that the addition of terra rossa provides more inclusions to the paste, enhancing its workability and preventing the propagation of fractures. However, other potters indicate that the addition of these clays increases the plasticity of the clay. Artisans from Mouliana argue that the use of these clays reduces the risk of fractures due to their content in sands. Finally, potters from Kentri state that pastes prepared with these clays do not permit the creation of thin walls but, instead, provide high resistance to the paste in order to survive the firing process. In short, the potters of the island only agree in arguing that the addition of clays with more inclusions contributes to minimising the risk of collapse due to the propagation of fractures during the manufacturing process.

Although we may infer that pottery can be perceived in a certain way and that the human mind presents the same structural organisation in cognitive terms worldwide, it must be also considered that the way in which perception is categorised is not 
essentialist but contingent. Perception responds to cultural constructs established from a relational connection among the whole materiality that surrounds us (Jones, 2002). In this sense, B. Sillar (1997) has documented in the Peruvian Andes how the cultural perception that potters make of resources and technology determines the emergence of a specialised pottery production in functional terms. In fact, there are usually no constraints in the properties of the raw materials which restrict its use to the manufacture of certain types of pottery vessels exclusively.

Furthermore, as pointed out by Rice (1996), ceramics' properties do not have to be directly related to intentional technological choices, but may respond to certain cultural traditions related to unconscious practices. In this way, many of the physical properties of the materials were perhaps not even perceived. As we shall see in the next section, individuals also frequently act by means of a series of habits, unconscious behaviours learned as a result of social interaction that are imperceptible to those who undertake them. Habits would be, therefore, at the opposite end of this functionalist behavioural trend in which potters perceive, understand and, consequently act on all the phenomena surrounding their existence.

Therefore, evolutionary ecological and functionalist approaches overstate the ability of the individuals to rationalise their needs and technological actions. Thus, these perspectives minimise the importance of structures, historical processes and habitus in the production and reproduction of society and individual practice. Potters can learn the technical gestures and chaines opératoires associated with specific technologies through imitation processes without necessarily knowing their scientific or functional rationale. Thus, it is not necessary to be aware of the scientific foundations underlying each technology to get a product suitable in social terms. It is often enough to follow a certain routine in pottery production for obtaining satisfactory end products.

In many cases, potters find the justification for their actions not on a western and modern scientific basis, but in the contexts in which they have learned and become familiar with a specific rationale, which they then express ideologically by means of discursive and non-discursive ways of communication (Budden and Sofaer, 2009). In this sense, besides trying to address the potter's technical skills involved in its production (i.e., the techno-science), it is equally important to understand other factors and kinds of knowledge, such as legends or myths, which also enable the establishment and maintenance of certain chaînes opératoires and technological traditions (Boivin 2004).

Moreover, as we observed in north-east Ghana, myths can also integrate the functionality of the vessels in their explanations. For instance, the son of a craftswoman from the Kusasi ethnic group states that while he was learning to make clay toys his mother explained a myth to him about the origin of the pottery production. His mother argued that their ancestors needed pots for cooking and storing water; hence, the women made unfired clay pots but they could not be used because they suddenly crumbled when it got in contact with water. It was at that point when the knowledge 
of males regarding the application of heat and fire on mud made it possible to obtain usable pottery. This myth is structured around the functionality of vessels and the manufacturing process, but it is also imbued with social, symbolic and ideological aspects. For example by giving males a key role in the creation of pottery it also justifies the existence of a patrilineal social organisation. Moreover, in this myth there is a clear representation of fertility which is associated, on the one hand, with women and earth and, on the other with men and fire. It is the combination of both elements which results in the creation of a usable vessel for the society.

Furthermore, in this functionalist perspective, evolutionary and ethnocentric viewpoints involving a technological determinism in which material culture can be only efficiently manufactured and used in one way are often predominant (Pfaffenberger, 1992). This is therefore a static approach which obeys universalistic physical standards that have little to do with the huge dynamism and cultural diversity that actually exists in the world. In consequence, the passive view and the secondary role that functionalist behavioural perspectives give to non-biological or non-practical dimensions of materiality has been frequently criticised (Dietler and Herbich, 1998).

As noted by Livingstone-Smith (2000), this functionalist approach makes assumptions on ancient technologies through theoretical concepts essentially created from modern science. Thus, these approaches do not usually take into account the phenomena that characterise the reality of ancient societies. As pointed out Dobres and Hoffman (1994) such perspectives lead to "technological somnambulism" in which the technical optimisation becomes the reason for the individual's behaviour. Such criticism to functionalism highlights that the actions and aims of the potter, whether or not he has a utilitarian purpose, are always related to the ideational dimension and are made according to a series of individual and community social needs. Thus, although there might be an intense functional adaptation of the vessels, this fact does not preclude that the features of the product and their production and use processes have other implications beyond the mere biological or practical needs.

Besides this criticism, material sciences studies often have a high degree of ambiguity and contradiction (see, for instance, Stone and Young, 1990 vs. Schiffer, 1990; Steponaitis, 1984 vs. Müller et al., 2009). Moreover, there is a large multiplicity of parameters taking part simultaneously in the properties of the vessels and their functional optimisation. In this way, the inferences established may have little resolution and result often in a "ceramic possibilism" (Rice, 1996). As P. Rice says, "what element does not affect the physical properties of a cooking pot?"

In short, beyond the functional benefits of certain ceramics, which are manifested in its opposition to others, there are many social, ideological and symbolic factors which affect their consumption and, by extension, the features of the artefacts. Moreover, highly functional specialised productions do not always exist in all societies and situations. Thus, in many cases concepts such as multiplicity, polyfunctionality, lack of specialization and redundancy prevail (Calvo, 2007), 
hindering the establishment of linear, universalistic and direct connections between technological, morphological and functional issues. In consequence, two vessels with the same form and technology should not be necessarily related to an identical use but to a wide range of functional possibilities and choices.

As some authors highlight (Calvo, 2007; Jones, 2002), the function of an artefact must be ultimately related and interpreted considering many other aspects. The concept of function is abstract, contingent and loaded with cultural and social connotations. Hence, it is not feasible to explain all the features of ancient ceramics, as well as their meaning and significance, by means of universalistic functional classifications focused on western and modern concepts of maximisation and technological efficiency. This is not only because physical and practical elements influence the role of the objects, but also because their functionality depends on cultural and symbolic parameters. These facts, together with the existence of pottery productions lacking functional specialisation but linked with other phenomena (e.g., polyfunctionality, redundancy, etc.), makes the possibility of establishing static and unchanging universalistic functional categories by means of a typological and technological basis impossible.

Cautiousness should be exerted in this regard to be aware that a single artefact (Calvo, 1999, 2007), as well as two identical ceramic pieces, can have multiple functions. Moreover, that the same function can be satisfied by means of more than one form (Miller, 1985). An example of the first phenomenon was ethnographically observed in the potter community of Quinua in the 1980s (Peru), where the use of the same type of vessels for multiple purposes, activities, contents and events was documented (Arnold, 1984). Similarly, in north-east Ghana the highly symbolic ceramic types used in shrines are also the same ones used in several domestic activities. As noted earlier, these examples are evidence that there are a number of vessel's features irrelevant in practical terms which respond to the potter's cultural patterns as well as to aesthetic and social factors (Calvo, 2007; West, 1992).

Accepting these assumptions implies considering a dynamic conception of pottery in which it is not an isolated and unchanging element but a production located in a given space and time as well as in a specific culture and human group. Ultimately, pottery reflects complex phenomena that do not only relate to techno-functional aspects. Besides this, their technological traits are also determined by sociocultural, historical, economic, environmental, ideological, symbolic and religious factors (Gosselain, 1994; Prieto, 1999; Vidal, 2008b).

Therefore, when issues concerning fabrics, forms and functions are addressed in pottery production it should be kept in mind that ceramics can be only understood within the social and technological context in which they are conceived. Hence, multiple external factors that also determine the form, materials and functions of the vessels should be considered along with the physical features of the pottery itself. Especially in the case of prehistoric pottery, technical and functional requirements can be in many cases minimal, since a minimally shaped and fired artefact is enough 
to obtain a product valid for a large number of varied uses. This low functional requirement of pottery has led to the use of forms and materials which do not respond to a high functional specialisation, but to the multiple non-functional factors just discussed (Calvo, 2007; Gosselain, 1994; Pfaffenberger, 1992; Stoltman, 2001).

\subsection{Possibilities and Limitations of the Functionalist Approach}

Pottery is more or less adapted to perform a function, but the principles governing this parameter and the features of the ceramic object are determined by cultural factors. This explains why in most cases it is possible to observe totally different objects intended for the same function, i.e., different technological choices have been made to satisfy the same need. Nevertheless, as unilinear cultural evolutionism states, this premise does not preclude that certain uniformity may be achieved in objects intended for the same function regardless of cultural factors. In this sense, it must be considered that in some cases the potential choices available in the search for an object which can fulfil an efficient functional adaptation may be quite limited. Thus, this search can lead to a homogenization of the technological choices carried out, regardless of the cultural, social or economic basis of the human group that has created the pottery.

It cannot be forgotten that objects are created to be used and, as pointed out by I. Hodder (1991), that their functional, systemic and ideational dimensions are closely interrelated. In consequence, one cannot be addressed without reference to the other. As previously stated, functional aspects, along with many other parameters discussed above, deeply influence the meanings given to material culture. So, vessel function cannot be ignored if we intend to analyze meaning structures. In this sense, it may be useful to consider the physical properties of the materials to properly interpret the archaeological record. For example, as repeatedly argued, the composition of the paste and the nature of the inclusions, tempers and clays can provide multiple attributes to the vessels. These properties can influence aspects such as the durability, a parameter which may eventually affect the social role of ceramics (Jones, 2004).

The material dimension of objects cannot be totally precluded and substituted by their ideational aspects. Their materiality and physical properties also influence how they are perceived and used, therefore, representing one of the many factors that determine their significance. The key is to achieve a balanced viewpoint between the materialist and idealist dimensions of pottery, as they are not antagonistic or contradictory; on the contrary, they cannot be understood in isolation but as an integrated, interrelated and contingent whole. Thus, functionalist perspectives provide a wide range of technological choices in materialistic terms that people might have in mind when manufacturing objects. For example, in Upper East Ghana, Mamprusi people highlight that they consider the lightness and resistance to impact 
of the pottery when purchasing the vessels. However, this does not exclude that other factors also influence ceramics acquisition (Calvo et al., 2013).

Given these considerations, it is clear that we must consider several interpretative frameworks when studying ceramic technology. In this way, materialistic approaches promote research lines focused on the study of ceramic artefacts that strengthen the relationships existing between the physical characteristics of the end products and the processes of manufacture, use and deposition of the pottery. Moreover, although the results obtained through the functional analysis of pottery are not conclusive, this approach also informs about the potter's rationale and interests. Hence, considering the function of the pottery through compositional and morphometric analyses as well as its relation to the production processes and contexts of use can be essential to understand the variability of the techniques and materials identified in the ceramic record. In short, this perspective allows addressing certain aspects regarding the organisation of production, such as the potter's skills, as well as the society as a whole.

Vessel function may influence the several processes involved in the manufacture of ceramics and the features of the end product, from its shape and size to its paste, firing procedures, surface colour and treatments, decorations, etc. Therefore, despite its limitations, functionalist approaches may address the complexity embedded in any pottery item.

As documented in various ethnographic studies (e.g., Albero and Puerta, 2011; Arnold, 1985, 2000; Gosselain et al., 1996; Varela, 1990), potters from many societies show different technical behaviours according to the diverse functions of the pottery. Thus, despite its theoretical restrictions, the study of vessel functionality represents an interpretive framework that can lead, at least in some cases, to understand why potters manufactured their products in a certain way. Therefore, in these cases, this perspective also permits us to approach the significance of artefacts in any society and understand certain depositional patterns related to the specific use of the vessels.

Such approaches usually provide a large corpus of data and a series of hypotheses that acquire validity when they are reformulated within specific use contexts, i.e., those of the society in which the pottery was used and loaded with meaning. It is only by combining the morphological and techno-functional approaches to the vessels with the results of experimental tests and organic residue analysis that the question of the functionality of pottery may be tackled. It must not be forgotten that both the function and technology of the vessels are closely linked to certain contents and activities. Thus, in archaeology it is very common to consider that ceramic containers were complementary to the product they contained. In this way, any peculiarity in the vessel which may be interpreted as a potter's signature is not only aimed at identifying the ceramic objects, but also the products they contain (Carreras and Nadal, 2003).

In this sense, the combination of techno-functional approaches with methods such as Gas Chromatography Mass Spectrometry (GC-MS) may contribute substantially to the study of the relations existing between contents, functions, types 
and fabrics. This approach necessarily involves the implementation of all the results obtained from these studies along with a deep analysis of the archaeological context in all its complexity, i.e., considering the multiple interconnections existing between all the biotic and abiotic materials: contexts, fauna, pollen, charcoal, phytoliths, plants, ceramics, metal objects, architectural structures, etc. In this sense, it must be remembered that pottery, as any other item of material culture, interacts with a wide range of objects and materials, such as other containers made of wood or leather, in their daily use (Mannoni, 2007).

In the long term, this strategy would allow us to know how each society promotes a close relation between certain specific places, biotic and abiotic resources that is organised through specific culinary traditions and ways of food preparation and management, as well as by means of characteristic consumption and depositional patterns. Functional approaches on ceramics can also provide information about food preparation techniques and culinary tastes, since certain ceramic fabrics and forms can be strongly related to different cooking methods (e.g., Albero and Puerta, 2011; Fernández Navarro, 2008). Also the characteristics of the fabrics can provide a particular flavour to the foods cooked in the pottery due to the ability of the vessels walls to absorb organic substances and retain their taste (Barley, 1994; Skibo, 1992).

In short, the data provided by science-based material approaches in the study of ceramic fabrics and pastes implies a first step towards the establishment of strategies that aim at meeting the complex functional interrelations existing between the elements integrating the archaeological record. Anyway, it should be highlighted that this techno-functional study of pottery based on the properties of the materials may have several constraints to approach the functional dimension of many ceramics produced in domestic contexts for several reasons.

First, we have to be aware that such approaches often provide results which are only significant in terms of "technological possibility" or, in the best case, of the denial of certain functional capabilities. In many cases, solid and consistent conclusions cannot be proposed regarding the specific functions associated with the vessels. For this reason, it is more convenient to undertake a comprehensive analysis of the context in which the pottery is located and its interaction with other materials. Moreover, it should be considered that the results obtained by means of other procedures such as absorbed residue analysis are also more consistent and reliable to approach the use and function of the ceramics.

Second, techno-functional approaches on ceramic fabrics may be more fruitful in wheel-thrown pottery productions, which are characterised by a high standardisation of the vessels and a mass production, as well as a clear commercial interest. In these cases, highly specialised pottery assemblages are usually predominant and, in consequence, each type of ceramic object is made according to its specific function. Since its origins, science-based material approach has been closely related to the study of this kind of pottery production. 
In contrast, as previously noted, in domestic production this functional specialisation of ceramics is usually absent or just restricted to very specific types of vessels, such as crucibles. In these societies, the pottery production is often more influenced by phenomena such as multiplicity, multifunctionality, lack of specialization and functional redundancy. Anyway, in these cases, a techno-functional approximation may be useful to question the existence of correlations between forms, fabrics and functions to demonstrate on the basis of facts and not by mere empirical assumptions which kind of functional phenomena are involved in pottery production. It would allow, for instance, objectively ruling out the existence of specialised behaviours towards the functional optimisation of the vessels manufactured. 